\title{
Blaming the Ref: Understanding the Effect of Unexpected Emotional Cues on Family Violence
}

\author{
Alexander J. Cardazzi \\ West Virginia University, ajc0056@mix.wvu.edu \\ Brad R. Humphreys \\ West Virginia University, brhumphreys@mail.wvu.edu \\ Bryan McCannon \\ West Virginia University, bryan.mccannon@mail.wvu.edu \\ Zachary Rodriguez \\ West Virginia University, zr0009@mix.wvu.edu
}

Follow this and additional works at: https://researchrepository.wvu.edu/econ_working-papers

Part of the Behavioral Economics Commons, and the Sports Studies Commons

\section{Digital Commons Citation \\ Cardazzi, Alexander J.; Humphreys, Brad R.; McCannon, Bryan; and Rodriguez, Zachary, "Blaming the Ref: Understanding the Effect of Unexpected Emotional Cues on Family Violence" (2020). Economics Faculty Working Papers Series. 52. \\ https://researchrepository.wvu.edu/econ_working-papers/52}

This Working Paper is brought to you for free and open access by the Economics at The Research Repository @ WVU. It has been accepted for inclusion in Economics Faculty Working Papers Series by an authorized administrator of The Research Repository @ WVU. For more information, please contact ian.harmon@mail.wvu.edu. 


\title{
Blaming The Ref: Understanding the Effect of Unexpected Emotional Cues on Family Violence
}

\author{
Alexander J. Cardazzi \\ West Virginia University \\ Bryan C. McCannon \\ West Virginia University
}

\author{
Brad R. Humphreys \\ West Virginia University \\ Zachary Rodriguez \\ West Virginia University
}

August 24, 2020

\begin{abstract}
Domestic violence generates long-term effects on offenders, victims, and other household members. Insight into triggers of family violence can inform policy and improve services aimed at reducing abusive behavior. We investigate potential domestic violence triggers by analyzing unexpected losses in National Basketball Association games. The literature identifies increasing in-home violence after unexpected losses in the National Football League. Combining information on referee accuracy and fatigue, we develop a unique identification strategy to explore the impact of human error on family violence following unexpected losses. Results indicate that as referees are more accurate (more rested) in unexpected losses, family violence decreases, suggesting that the ability to place blame for a loss on referees increases the likelihood of violent outbursts. Further investigation shows that these results concentrate in games where referees are less rested and betting markets were less certain of the game outcome.
\end{abstract}

JEL Codes: J44, K42, Z22

Key Words: Domestic violence, job performance, emotional cues

\section{Introduction}

Family violence represents a pervasive problem in communities around the world. Reductions in health, lost productivity, along with policing and adjudication costs account for just a few of the costs associated with family violence. Peterson et al. (2018) estimated lifetime costs of family violence at $\$ 103,767$ per female victim and $\$ 23,414$ per male victim, generating a national economic burden of nearly $\$ 3.6$ trillion. Family violence affects individual members differently. Most cases involve violence toward women, as about 1 in 4 women (25.1\% or 30 million) in the United States experienced a form of family violence (sexual, physical, and/or stalking) in their lifetime (2015 National Intimate Partner and Sexual Violence Survey). In families with children, family violence can have serious effects on child development and behavior.

Research identifies negative effects of family violence on child emotional health (Greene et al., 2018), and finds that these effects spill over onto their peers through emotional or disruptive behavior in school (Carrell et al., 2018). The 2018 National Crime Victims' Rights: Crime and Victimization Fact Sheet reported 
that " $67 \%$ of violent victimizations were committed by a relative, $54 \%$ by an intimate partner, $43 \%$ by an acquaintance (either well-known or casual), and $42 \%$ by strangers.", further study of family violence and its causes can mitigate or even prevent these traumatic, long-term effects for households.

Given the large costs and wide prevalence of family violence, our analysis focuses on two types of family violence: coercive behavior and expressive aggression (Breiding et al., 2015). Family violence that affects household roles and incentives represents an example of coercive behavior. Tur-Prats (2019) offers evidence that households where other family members handle childcare, thus allowing the wife to work, experience less intimate partner violence than households where a wife raises children at home.

The cost of violence is high for working wives, as it results in reduced household productivity. Women who control resources for the household also face an increased risk of family violence. Hsu (2017) provide evidence of this risk by analyzing the timing of welfare payments to female TANF recipients. Hsu finds increased incidence of assault and intimidation before payment dates, suggesting men use the threat of violence to gain control of household resources before payments get disbursed to women. If women can maintain control of resources under the threat of violence, evidence shows that women recipients of cash, vouchers, and food transfers experience reductions in intimate partner violence (Bobonis et al., 2013, Hidrobo et al., 2016).

Aggression represents another important form of family violence. Aggression can be triggered by emotional stimuli, an example of expressive aggression. The unexpected nature of expressive aggression complicates the identification of triggers for these events. Violent episodes can be provoked by victims directly (Babcock et al., 2004) or through an offender's alcohol or substance abuse (Klostermann and Fals-Stewart, 2006). Random events like the sudden death of friends or family (Marshall et al., 2011), unintended pregnancy (Martin and Garcia, 2011), or poor stock market returns (Huck, 2018) have been identified as triggers for family violence. Following Card and Dahl (2011), we focus on violent aggression generated by the uncertainty of outcome in sports competitions.

Some unexpected game outcomes reflect extenuating circumstances like fan interference in play, for example Jeffrey Maier in Game 1 of the 1996 MLB American League Championship Series and Steve Bartman in Game 6 of the 2003 MLB National League Championship Series, as well as other forms of human error. Evidence suggests unexpected sports outcomes affect many fan decisions following games. For example, $\mathrm{Ge}(2018$ ) found evidence of increased tips to New York City taxi drivers after unexpected wins, Eren and Mocan (2018) found evidence of increased judicial sentencing on the next workday after unexpected losses, and Potoski and Urbatsch 2017) found evidence of decreased voter turnout on Tuesdays after "competitive" Monday Night Football games. Violence and crime have also been shown to increase after unexpected game outcomes. Sarmiento-Barbieri et al. (2018) found evidence of increased crime after unexpected losses in home soccer matches in Brazil.

Card and Dahl (2011) represents the paper most closely related to ours. Card and Dahl (2011) found evidence that unexpected outcomes in professional football games trigger family violence. Their results showed that domestic violence increased in cities home to National Football League teams following games the home team was expected to win but instead lost. Their results imply substantial costs for households impacted by emotional outbursts following dashed expectations of home team wins. We could mitigate these violent outbursts from further analysis of triggers of violence.

We contribute to the literature by confirming this also occurs following unexpected losses in a different sport, the National Basketball Association (NBA), and investigating a potential mechanism through which unexpected sports outcomes trigger family violence. Previous research did not investigate mechanisms. To identify a sports-related trigger for family violence, we combine information on NBA referee accuracy and 
fatigue to explore the impact of human error on NBA game outcomes. Using measures of events that contribute to referee fatigue like distance traveled between games refereed, travel-related changes in times zones, and the number of days rest between games worked by specific NBA referees, we explore fatigue as an explanation for increased incorrect calls in close NBA games. Our identification exploits detailed information contained in the NBA Last Two Minute Report, a league-produced report which contains detailed, objective post-game evaluations of the accuracy of referee calls at the end of close NBA games. Our results confirm previous research reporting that fatigue negatively affects referee accuracy (Weston et al. 2006).

To investigate referee accuracy as a trigger for family violence, we adopt the empirical approach used by Card and Dahl (2011) to analyzing crime data from eight counties home to NBA teams following unexpected home team losses. The length of the NBA season provides a large enough sample of games to analyze the impact of unexpected game outcomes on family violence. Results show in-home violence against women increases after unexpected losses, and also increases in counties where the home team lost unexpectedly. The scope of sports-related domestic violence appears larger than previously thought, as the NBA season contains many more games than the NFL season.

We investigate the role played by referee fatigue on game outcomes and how this further triggers violence against women, a previously unexplored area. If a referee makes enough incorrect calls during a close game, blaming the loss on human error could trigger violent outbursts among male fans, as family aggressors often project blame for negative events onto their victims. We find that as referees are more rested, and thus make more correct calls, family violence decreases after unexpected NBA losses. We interpret this result as reflecting human error as a mechanism for triggering family violence. As expressive violence needs a stimulus, the ability to lay blame for an unexpected loss on referee mistakes triggers aggressive behavior.

\section{Data and Setting}

Card and Dahl (2011) found substantial increases in family violence in cities home to NFL teams after unexpected home team losses and attributed this to negative emotional cues generated by these losses. Card and Dahl (2011) treated upset losses as homogeneous outcomes. However, upset losses can differ in terms of why they occur, and the explanation for why upset losses occur might affect the strength of any negative emotional cue these losses generate, and the corresponding impact on domestic violence. Literature on the psychology of family violence identifies loss of control and victim blaming as common justifications used by offenders (Ali et al. 2016). If fans identify officiating as the cause of an unexpected loss, then they may be more likely to project blame onto their spouse or partner, increasing the likelihood of a violent episode.

Investigating this requires an empirical setting where specific explanations for unexpected game outcomes can be identified. Recent policy initiatives instituted by the NBA make it possible to quantify referee accuracy at the end of close games, and thus determine the role played by referee mistakes in unexpected NBA team losses. The NBA recently implemented a policy of evaluating referee decisions at the end of close games with the intent of increasing transparency and the quality of officiating. The NBA evaluates referee performance at the end of games where the score difference falls within a certain point margin and makes the results of these evaluations public. Objective evaluation of referee performance in close games provides an opportunity

to quantify the effect of human error on game outcomes. We explore this effect as a channel for triggering family violence. 


\subsection{The Last Two Minute Report}

In February 2015, the NBA announced a new transparency initiative in its officiating program called the Last Two Minute Report ("L2M") 1 . The NBA publishes an L2M report for all "close" games. The NBA defines a close game as any game where the score difference is three points or fewer at any time in the last two minutes of the fourth quarter. If a game qualifies for an L2M report, the NBA initiates an evaluation of "all calls and material non-calls that occur in the last two minutes", and then publicly releases these evaluations as an L2M report ${ }^{2}$

The L2M report contains a play-by-play description of when each referee call was made, the referee call, which player committed the infraction, which player the offending player committed an infraction against (if applicable), and the review decision for the referee call. The most interesting feature of the L2M, the review decision clearly states whether or not a call or no-call was correct. Third party reviewers, trained in the same way as NBA referees on how to evaluate play, determine the correctness of each referee call for an L2M.

Once determined, these third party evaluations are approved by "ref ops senior staff (former officials) and senior b-ball ops personnel, much to the chagrin of NBA referees" 3 . Since L2Ms evaluate both referee calls and material non-calls, evaluations take one of four forms: correct call, correct no-call, incorrect call, and incorrect no-call. We define and discuss both correct calls and correct no-calls as "correct calls", even though they are different types of correctness. Also, L2M reports contain a hyperlink to video replay of the event in question, allowing anyone to watch the replay in order to understand how the reviewers reached their decision.

Given that the NBA makes L2Ms public, we use this objective evaluation of referee decisions to identify how correctly referees officiated a particular basketball game in the last two minutes of play. Given an objective measure of human error during close games, we can further assess the impact, if any, on domestic violence. Several factors prevent us from being able to use this measure of referee correctness in our analysis of unexpected losses. Since the L2M is published only after close games, there will be bias in the sample of games in which we measure human error as the sample will not contain games that were unexpected losses but never met the point threshold criterion for the release of an L2M. Analyzing only close unexpected losses potentially biases our results. To mitigate this problem, we use the L2M to measure referee correctness conditional on referee fatigue. Exploiting the correlation between fatigue and correctness, we can explore more deeply the impact of human error as a trigger for intimate partner violence. Also, the small number of L2M reports produced to date limits the power of our analysis.

\subsection{National Incident-Based Reporting System Crime Data}

We measure family violence using data from the National Incident-Based Reporting System (NIBRS). NIBRS data include individual reports of violence made to police agencies, but are not necessarily associated with an arrest for reported incidents. Each NIBRS incident report contains information on both the victim

\footnotetext{
${ }^{1}$ Other components of this initiative included "the launch of the NBA Replay Center", real-time postings on NBA.com, the creation of the Twitter handle @NBAOfficial to disseminate the replays used by referee evaluators to make decisions during replay reviews, and bi-weekly rule "points of emphasis" memos that are sent to teams, referees and the media. Official Press Release, "NBA to share 'Last Two Minutes' officiating reports beginning March 2" NBA.com, 27 February 2015.

${ }^{2}$ When the L2M was first implemented in the middle of the 2014-2015 season, a game would trigger an L2M report if the score difference was within five points or less at the two minute mark of the $4^{\text {th }}$ quarter. The NBA changed to its current system at the beginning of the 2016-2017 season.

${ }^{3}$ MacMahon, Tim. "Referees association calls L2M reports 'flawed process,' league office disagrees." ESPN.com, 16 March 2018.
} 
and offender (age, gender, relationship, if any) and details on the incident (time and date, county where the incident occurred, and injuries suffered in the incident). Following Card and Dahl (2011), we classify family violence as at-home incidents of male-to-female simple assault, aggravated assault, or intimidation by a spouse, partner, or boyfriend/girlfriend. We focus on male-on-female violence occurring at home between $6 \mathrm{PM}$ and 6AM, periods during or after NBA games. NIBRS contains a complete, detailed record of all reported incidents of family violence and information on the timing and location of incidents that permits matching them with NBA game day information.

NIBRS data may not reflect all incidents of family violence that occur, as this type of violence often goes unreported to police agencies. Card and Dahl (2011) show that even with this limitation, a comparison of reported incidents in NIBRS to other survey data on domestic violence, for example the National Violence Against Women Survey, implies that NIBRS contains a high proportion of serious violent events experienced by women age 18-54. Another limitation is that reporting by NIBRS partner agencies is voluntary and low. However, reporting rates increased from $25 \%$ in 2006 to $29.3 \%$ as of 2016 (McCormack et al., 2017).

We collect NIBRS daily report data on family violence from 8 counties containing an NBA teams over the period 2012-2018. Table1 1 displays the county and team names along with average and median domestic violence incidents for each county in the sample per $6 \mathrm{pm}$ to $6 \mathrm{am}$ time frame. Domestic violence incidents vary substantially across these counties. This may reflect differing numbers of police agencies in each county.

Table 1: Family Violence Incidents by County

\begin{tabular}{lcccc}
\hline County & Mean & St. Dev. & Median & Max \\
\hline Cuyahoga(Cavaliers) & 4.95 & 2.72 & 5 & 15 \\
Dallas (Mavericks) & 0.40 & 0.65 & 0 & 4 \\
Denver (Nuggets) & 1.84 & 1.47 & 2 & 8 \\
Harris (Rockets) & 0.05 & 0.22 & 0 & 2 \\
Maricopa (Suns) & 0.24 & 0.48 & 0 & 3 \\
Milwaukee (Bucks) & 3.46 & 2.48 & 3 & 18 \\
Oklahoma (Thunder) & 0.02 & 0.15 & 0 & 2 \\
Salt Lake (Utah) & 2.23 & 1.89 & 2 & 11 \\
\hline
\end{tabular}

This table summarizes reported daily incidents of family violence as defined in Card and Dahl (2011) (simple assault, aggravated assault, and intimation) between $6 \mathrm{PM}$ and $6 \mathrm{AM}$, per county in our sample.

Table 2 contains information about NBA games that involve teams in counties with and without NIBRS data. 3,893 NBA games in the sample were played by a team in a county with NIBRS domestic violence data and 4,431 were played by teams with no connection to the NIBRS data. For example, the 3,893 games include all games the Cleveland Cavaliers play, whether they are the home or away team. One issue that could arise from a lack of complete crime data would be that domestic violence in counties with NBA teams and NIBRS crime data could systematically differ from violence in counties with NBA teams and no NIBRS data.

From Table 2, there does not appear to be substantial differences across NBA games with or without matched NIBRS data. The final two columns in the table show the t-statistic for a difference in means test assuming equal variance and the corresponding p-value for each t-statistic. The null hypothesis of equal means cannot be rejected for many key variables, including the fraction of games that triggered an L2M report. In cases when the null is rejected, the actual differences are not large and likely not economically meaningful. 
The bottom panels of Table 2 contain information about L2M outcomes in NBA games with and without NIBRS information. From the top panel, $16.4 \%$ of the games with matched NIBRS data resulted in the publication of an L2M report and games without matched NIBRS data generated the exact same fraction of L2M reports. From the t-tests for differences in means reported on the bottom panel, games in and not in NIBRS are not statistically different in terms of the correctness variables, thus suggesting balance in sample characteristics.

Table 2: Basic Summary Statistics for NBA Games

\begin{tabular}{l|ccc|ccc|cc} 
& \multicolumn{7}{|c|}{ In NIBRS } & \multicolumn{3}{c|}{ Not In NIBRS } & & \\
\hline & $\mathrm{N}$ & Mean & St. Dev & $\mathrm{N}$ & Mean & St. Dev & $t$-stat & $p$-value \\
\hline Playoff & 3,893 & 0.056 & 0.23 & 4,431 & 0.062 & 0.242 & -1.159 & 0.2465 \\
L2M & 3,893 & 0.164 & 0.37 & 4,431 & 0.164 & 0.37 & 0 & 1 \\
Nat'l TV & 3,893 & 0.267 & 0.442 & 4,431 & 0.247 & 0.431 & 2.084 & 0.0372 \\
Attendance & 3,893 & 17.753 & 2.341 & 4,431 & 17.8 & 2.458 & -0.893 & 0.372 \\
4th Q Pace & 3,893 & 95.269 & 8.168 & 4,431 & 94.333 & 8.057 & 5.25 & $<.01$ \\
Away Score & 3,893 & 99.508 & 12.15 & 4,431 & 99.13 & 11.874 & 1.431 & 0.1524 \\
Home Score & 3,893 & 102.442 & 11.951 & 4,431 & 101.728 & 11.896 & 2.726 & $<.01$ \\
L2M Length & 3,893 & 7.889 & 4.481 & 4,431 & 7.919 & 4.557 & -0.302 & 0.7624 \\
numberOfVeterans & 3,893 & 2.698 & 0.468 & 4,431 & 2.687 & 0.476 & 1.061 & 0.2885 \\
Ref Game Exp. & 3,893 & 834.883 & 253.604 & 4,431 & 828.898 & 252.982 & 1.076 & 0.2822 \\
Ref Season Exp. & 3,893 & 14.097 & 3.612 & 4,431 & 14.025 & 3.606 & 0.908 & 0.3638 \\
Game Length & 3,889 & 136.062 & 11.741 & 4,429 & 135.391 & 12.131 & 2.561 & 0.0105 \\
Tipoff Time & 3,893 & 0.836 & 0.073 & 4,431 & 0.817 & 0.087 & 10.831 & $<.01$ \\
Days Off (mean) & 3,893 & 2.959 & 1.521 & 4,431 & 3.022 & 1.42 & -1.945 & 0.0518 \\
Days Off (median) & 3,893 & 2.688 & 1.498 & 4,431 & 2.722 & 1.345 & -1.084 & 0.2786 \\
Distance (mean) & 3,893 & 0.884 & 0.359 & 4,431 & 0.91 & 0.427 & -3.017 & $<.01$ \\
Distance (median) & 3,893 & 0.838 & 0.441 & 4,431 & 0.845 & 0.506 & -0.674 & 0.5001 \\
\hline Correct Calls & 638 & 4.074 & 2.147 & 727 & 4.094 & 2.102 & -0.173 & 0.8624 \\
Correct Non-Calls & 638 & 8.868 & 4.528 & 727 & 9.05 & 4.694 & -0.728 & 0.4665 \\
Incorrect Calls & 638 & 0.135 & 0.368 & 727 & 0.127 & 0.349 & 0.41 & 0.6815 \\
Incorrect Non-Calls & 638 & 1.122 & 1.244 & 727 & 1.015 & 1.061 & 1.697 & 0.0899 \\
\# Correct & 638 & 12.942 & 4.867 & 727 & 13.143 & 5.01 & -0.751 & 0.4528 \\
\# of Total Calls & 638 & 14.199 & 5.045 & 727 & 14.285 & 5.178 & -0.31 & 0.7563 \\
\% Correct & 638 & 0.909 & 0.092 & 727 & 0.917 & 0.083 & -1.678 & 0.0937 \\
100\% Correct & 638 & 0.331 & 0.471 & 727 & 0.348 & 0.477 & -0.661 & 0.5085 \\
\hline
\end{tabular}

\subsection{Referee Fatigue}

Refereeing professional sporting events constitutes a high pressure occupation. Demands on physical and mental condition require that referees be conscious of effort expended during games and get adequate rest between games worked. The NBA outlines specific conditions for referee work load throughout the season through a collective bargaining agreement ("CBA") with the National Basketball Referee Association, the referees' union. In terms of consecutive games worked, the CBA tries to limit the number consecutive working days, and tries to limit the distance traveled by referees between games, so as to not cause stress on referees. Referee assignment complicates attempts to limit referee work load, as the NBA reveals referee game assignments incrementally throughout the course of the season. According to the CBA, referees are usually informed of their game assignments one month in advance, but later in the season, like in April

\footnotetext{
${ }^{4}$ Collective Bargaining Agreement between NBA Service Corp. and the National Basketball Referees Association, Article III, Section 13. Effective August 2015.
} 
and May, referees only lear of their upcoming assignments three weeks in advance. The NBA makes referee assignments public the day before games occur at 9AM Eastern Standard Time. The reasoning for limiting information regarding referee assignment has to do with its possible effects on the gambling market, a problem for the NBA in previous years ${ }^{5}$

In our analysis of correctness and fatigue, we empirically test the hypothesis that referee accuracy decreases with the amount of rest between games. Research in the sports medicine literature found a negative relationship between referee fatigue and technical performance in soccer matches. Evidence also indicates that increased fatigue affects referee decision-making throughout games (Schenk et al., 2018), and this effect reduces referee quality as the length of a match increases (Harper et al., 2014). In combination with our data collected from the L2M, we use information on the location of games worked by specific referees to generate referee fatigue measures that can be linked to L2M reports. A limitation to the L2M report is that it does not record which specific referee is responsible for a correct or incorrect call. Due to this limitation, our measurements of referee accuracy and fatigue will be aggregated to the crew-level, as almost all NBA games have a crew of three referees.

We create measures of fatigue using location-specific variables that could generate fatigue. We match distance traveled by each referee between consecutive games worked and the number of days off between games. After collecting this information for each referee on a crew, we aggregate to crew-level for each game and match the information to referee accuracy at the crew-level using the L2M report.

Referee accuracy measures collected from the L2M reports in Table 2 show that referees average approximately 14 calls or material no-calls in the last two minutes of close games. The NBA evaluates 13 of the 14 calls as correct on average, which means that referees are accurate $91 \%$ of the time in close games. This confirms statements made by NBA officials regarding referees accuracy in L2M games. Media reports quote NBA commissioner Adam Silver remarking that referees get "roughly 90\%" of calls correct in the last two minutes of close games ${ }^{6}$

We drop several games from our sample to address outliers in estimated fatigue. We first omit all games played in the 2011 calendar year due to the NBA lockout during that period 7 We also drop 250 games where at least one referee officiating the game had over 31 days of rest. These games mostly occur at the beginning of each season, based on the assumption that referees rest in the off season. These games may also include appearances by substitute referees and might be officiated differently than games involving regular NBA referees. Finally, we drop 74 games that had 4 (72 games) or 2 (2 games) referees.

\subsection{Sports Betting Market Data}

An important feature of many sports is the existence of well-organized betting markets on outcomes in these sports. Research frequently uses betting market outcome data to proxy for expected game outcomes, since sports betting markets are known to be informationally efficient and accurate predictors of actual game outcomes. We obtained betting market data for NBA games in our sample from the Sportsbook Review website (https://www.sportsbookreview.com/ "On-line sports betting authority since 1999"), a commonly used source of betting market data. We collected data on the final point spread and money line odds for each NBA game in our sample. Point spreads reflect the expected difference in the number of expected points scored by the home team and visiting team in each game, in the form expected visitor

\footnotetext{
${ }^{5}$ Eden, Scott, "How former ref Tim Donaghy conspired to fix NBA games." ESPN.com, 19 February 2019.

6 "Adam Silver on NBA officiating: 'Human error part of game." ESPN.com, 26 May 2016.

${ }^{7}$ The NBA began play on Dec. 25th 2011, so we drop 6 days of play in this season.
} 
points - expected home points. A point spread of -7 means the home team is expected to score 7 more points than the visiting team. Money line odds reflect the payoff on bets on one of the participating teams to win a game. We drop 9 games that missing either a money line or a spread from the sample.

Point spread betting does not focus on predicting the winner of a game. Instead, it focuses on the difference in the number of points that will be scored by each team in a game. Point spreads provide information about how much better one team is than the opponent. This permits identification of unexpected home team loses based on the final point spread on each game compared to the actual difference in points scored. For example, suppose the point spread on a game was -12 points. This point spread implies the home team is expected to beat the visiting team by 12 or more points. If the home team actually loses the game, it might be perceived as an unexpected loss. On the other hand a game with a point spread of +5 lost by the home team might not be perceived as unexpected, since the point spread implied that the home team would lose the game.

\subsubsection{Expected Outcomes from Betting Market Data}

Like Card and Dahl (2011), we assume that the point spread on an NBA game is an unbiased predictor of the difference in points scored by each team in that game. Figure 1 shows the distribution of point spreads (horizontal axis) and difference in points scored (vertical axis) for all NBA games in the sample. Note that actual differences in points scored have a much larger range relative to the point spread. Point spreads are less variable than actual point differences since they are expectations, or the center of distributions. Despite this, the average point spread in betting market data is usually not statistically different from the average difference in points scored.

Also like Card and Dahl (2011), we use the distribution of the point spread variable in order to define expected and unexpected wins and losses. We take the average of the point spreads in all games where the home team is expected to lose, point spreads with a positive values (average $=4.9$ ) and the average of the point spreads in all games where the home team is expected to win, point spreads with negative values (average $=-6.9$ ) and use these values to distinguish expected wins from expected losses. Figure 1 shows our identification strategy, where the upper left corner of the plot contains all of the upset losses. 


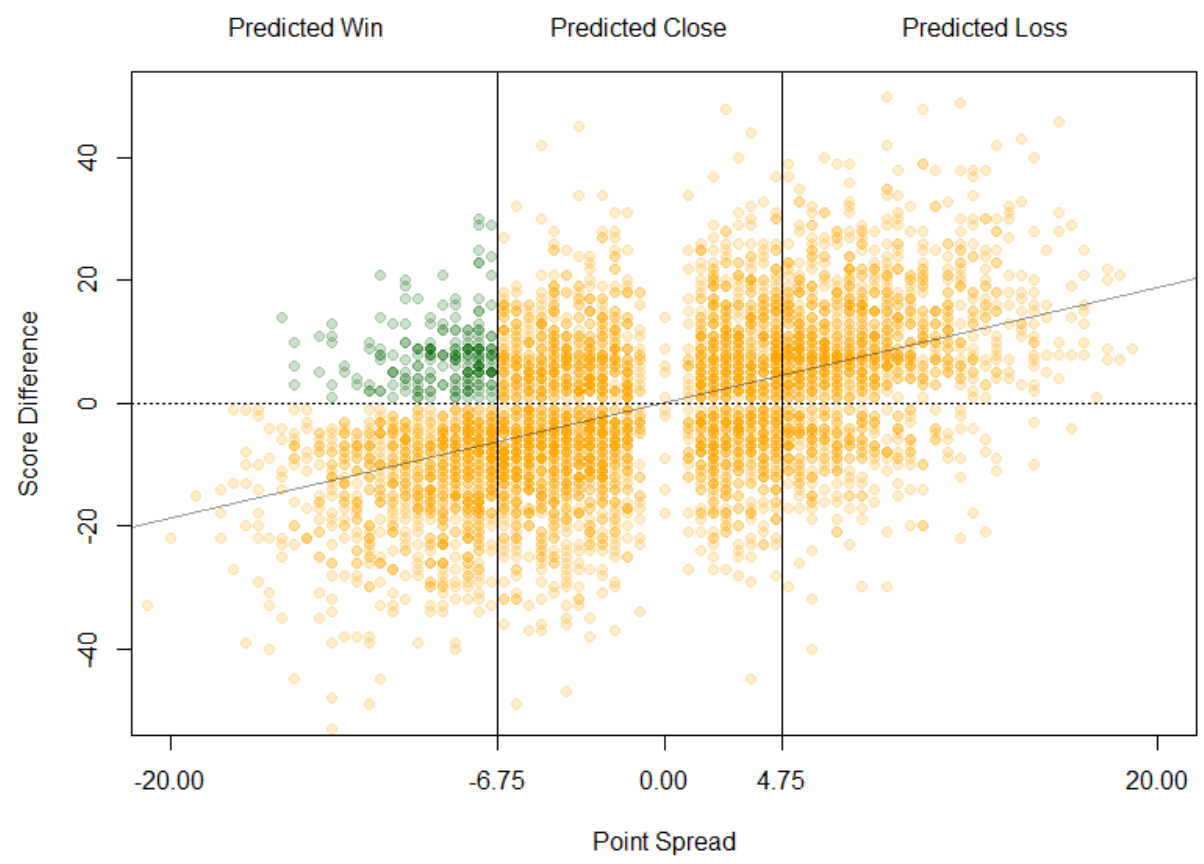

Figure 1: Point Spread vs Final Score Difference

Games with a point spread greater (less) than the average point spread in the sample are considered expected wins (losses) for the home team. So we define all games with a positive point spread greater than 4.9 as expected home team losses and all games with a negative point spread greater in absolute value than 6.9 as expected home team wins. This difference in cutoffs reflects home team advantage, a phenomena previously identified and studied in the sports betting literature (Schwartz and Barsky (1977); Feddersen et al. (2018)). Card and Dahl (2011) use a similar approach in their analysis of NFL games and point spreads, but use $+/-3$ points as their cut offs due to football's low scoring nature and a common NFL field goal being worth 3 points. While other studies in the literature, especially ones analyzing the NBA, use this same cutoff, we argue this is too small. Three points in an NBA game is much easier to score compared to three points in the NFL. Roughly, three points in an NBA game represents about $3 \%$ of the average score while three points in the NFL represents about $13.5 \%$.

\subsection{Other Control Variables}

Many reasons exist for why a referee makes an incorrect call at any point in an NBA game. An incorrect call could simply be due to human error. However, other game factors like late tipoff times, high paces of play, lengthier games, nationally televised games, or high game attendance could affect the accuracy of referee decisions. Variables reflecting each of these factors were are collected through NBA.com's API. We include these game features as control variables in our empirical analyses. 


\section{Empirical Strategy}

We estimate the effect of referee accuracy on family violence using a novel identification strategy making use of the NBA L2ms. As discussed previously, the NBA publishes post-game evaluations of referee performance as a L2M containing details about whether or not referees made correct calls in the last two minutes of close games. There are two main limitations to the L2M that prevent us from using referee correctness directly as a predictor of family violence in regression models. First, the relatively low number of games with L2Ms restrict the power of statistical tests. Second, since L2M only exist for close games, these games are more likely to be predicted as close ex ante in betting markets. This significantly reduces the number of upset losses with L2Ms to a small number

Due to these limitations of the L2M, we employ an alternative approach that uses information available for all games that plausibly affects referee decision making. We focus on variables linked to referee fatigue, like the number of days rest between games, changes in time zones between games worked, distance traveled, game tip-off time, and the level of air pollution in the city where the game is played. The next section discuss how we estimate the effect of fatigue on referee accuracy.

\subsection{Fatigue and Referee Accuracy}

Our identification of referee accuracy begins by assessing the relationship between referee fatigue and correct calls in NBA games with L2Ms. We estimate regression models explaining referee accuracy in the last two minutes of close game $i$, played at time $t$, using the following

$$
\text { Correct }_{i t}=\text { DaysOff }_{i t}+\text { Distance }_{i t}+\text { TipoffTime }_{i t}+X_{i t}+\epsilon_{i t}
$$

where Correct $_{i t}$ is a measure of referee crew decisions evaluated as correct in an L2M. We use both the number of correct calls and the precent of calls made judged to be correct as measures of referee accuracy.

We use several variables to proxy for referee fatigue in Equation (1), including the number of days rest between games, DaysOff ${ }_{i t}$ and the distance traveled between games in miles, Distance $_{i t}$. We also include the game tipoff time, Tipoff Time $_{i t}$, as a potential proxy for referee fatigue, as referees might be more fatigued at the end of games that start late in the day. Equation (1) also includes a vector of other covariates capturing game conditions, $X_{i t}$. This vector includes variables like game attendance, whether the game was nationallytelevised, the pace of play in the $4^{\text {th }}$ Quarter, and the actual time length of the last two minutes of play. We also specify a model to estimate the \# of correct calls using the same specification as in Equation (1), though we include a variable for the total number of calls made.

Equation 1 establishes the relationship between referee fatigue and referee mistakes in close games. Results from estimating the parameters in Equation (1) are discussed below, after discussing the entire empirical approach. As a preview, days off between games clearly explains observed referee accuracy in close games. The next step in our empirical strategy identifies unexpected outcomes in NBA games.

\subsection{Identifying Unexpected Outcomes}

In order to analyze the impact of emotional cues on family violence, we need to quantify how expected or unexpected an NBA game outcome was. Following Card and Dahl (2011), we estimate the probability of a team winning a game, $p_{i t}$, using the observed pregame point spread, $S_{i t}$ and the actual game outcome $y_{i t}$. In the notation used by Card and Dahl (2011), this function $f(\cdot)$ can be written as 


$$
\begin{array}{r}
f\left(S_{i t}, y_{i t} ; \lambda\right)=\lambda_{1} \cdot 1\left(S_{i t}<-6.9\right)+\lambda_{2} \cdot 1\left(S_{i t}<-6.9\right) 1\left(y_{i t}=0\right) \\
+\lambda_{3} \cdot 1(-6.5 \leq \\
\left.S_{i t} \leq 4.9\right)+\lambda_{4} \cdot 1\left(-6.9 \leq S_{i t} \leq 4.9\right) 1\left(y_{i t}=0\right) \\
+\lambda_{5} \cdot 1\left(S_{i t}>4.9\right)+\lambda_{6} \cdot 1\left(S_{i t}>4.9\right) 1\left(y_{i t}=1\right)
\end{array}
$$

where $1(\cdot)$ is an indicator function that returns a value of 1 or 0 depending on the specified logical condition. Again, the point spreads where we split the sample (-6.9 and 4.9) are the average point spreads for the subsample of games where the home team is favored (negative point spreads) and for the subsample of games where the visiting team is favored (positive point spreads). The parameters $\left(\lambda_{i} \mathrm{~s}\right)$ in this function identify specific ranges in the point spread distribution on NBA games where actual game outcome can be interpreted as unexpected. These parameters are defined as the averages of the positive and negative halves of the overall point spread distribution. Recall that negative point spreads indicate expected home team wins and positive point spreads indicate expected home team losses. In Equation 2, we are interested in $\lambda_{2}, \lambda_{4}$, and $\lambda_{6}$, as each proxies for emotional cues generated by upset losses, close losses, and upset wins, respectively. Much of our empirical analysis focuses on the impact of upset losses.

\subsection{Explaining Variation in Family Violence}

The number of at-home, male-on-female family violence events, $F V_{i t}$, occurring between the hours of $6 \mathrm{PM}$ and $6 \mathrm{AM}$ on night $t$ during the NBA regular season in county $i$ home to an NBA teams represents the main dependent variable in our empirical analysis. We explain observed variation in $F V_{i t}$ with the following empirical model

$$
{ }_{i t}=f\left(S_{i t}, y_{i t} ; \lambda\right)+\phi\left(f\left(S_{i t}, y_{i t} ; \lambda\right), \gamma_{i t}\right)+X_{i t}+\epsilon_{i t}
$$

We analyze variation in the number of incidents of family violence reported in county $i$ in time period $t$ ${ }_{i t}$ ) as a function of $S_{i t}$, the pre-game point spread, an indicator variable for the actual game outcome, $y_{i t}$, equal to 1 if the home team won the game and zero if the home team lost the game, and $\lambda$ parameters. The function $\phi$ ties together how referee accuracy, as measured through fatigue $\left(\gamma_{i t}\right)$, and game outcomes effect the number of family violence incidents. We also include $X_{i t}$ which are time-varying control variables. $\epsilon_{i t}$ represents a mean zero, possibly heteroscedastic random variable reflecting other unobservable factors affecting observed incidents of family violence in counties with NBA teams.

In Equation $2 \lambda_{2}, \lambda_{4}$, and $\lambda_{6}$ capture the effects of unexpected NBA game outcomes on family violence. We allow $\gamma_{i t}$ to enter into the model linearly. This way we can estimate a Poisson regression that relies on interaction terms 8

$$
\begin{array}{r}
\mu_{i t}=\lambda_{1} \cdot 1\left(S_{i t}<-6.9\right)+\lambda_{2} \cdot 1\left(S_{i t}<-6.9\right) 1\left(y_{i t}=0\right) \\
+\lambda_{3} \cdot 1\left(-6.9 \leq S_{i t} \leq 4.9\right)+\lambda_{4} \cdot 1\left(-6.9 \leq S_{i t} \leq 4.9\right) 1\left(y_{i t}=0\right) \\
+\lambda_{5} \cdot 1\left(S_{i t}>4.9\right)+\lambda_{6} \cdot 1\left(S_{i t}>4.9\right) 1\left(y_{i t}=1\right) \\
\left(\lambda_{2}+\lambda_{7}\right) \cdot 1\left(S_{i t}<-6.9\right) 1\left(y_{i t}=0\right) \gamma_{i t}+X_{i t}+\epsilon_{i t}
\end{array}
$$

In this specification, $\lambda_{7}$ is the effect of one more unit of referee fatigue on family violence during an upset loss. Using this identification strategy, we estimate the effect of unexpected game outcomes on family violence given the level of referee accuracy, proxied through fatigue. The combination of measuring the effect

\footnotetext{
${ }^{8}$ This equation only interacts $\gamma_{i t}$ with upset losses, though our analysis explores this interaction with all game outcomes and is robust to the different specifications.
} 
of referee fatigue on accuracy and how unexpected losses impact family violence structures referee accuracy as a potential mechanism of family violence. The following section provides the results from this analysis.

\section{Results}

\subsection{Referee Correctness and Fatigue}

Table 3 contains results from estimating Equation (1) using a subsample containing only games with L2M reports. This model explores the effect of referee fatigue on decisions in close games and establishes a link between fatigue and referee decision making. Figure 10 in the Appendix illustrates the typical travel path and time between games for a specific NBA referee over three seasons. Travel paths appear random season to season, along with the amount of rest between games. The League assigns referees to games, so referees cannot select themselves into specific games that might be easier to officiate. referees' work schedules and travel should be plausibly exogenous to unobservable factors affecting the quality of their decisions in games.

We use the percentage of correct calls and no-calls for referee crews per game and the total number of correct calls as measures of referee crew accuracy in close games. We employ several alternative proxies for fatigue based on distance traveled, days off between games, and game characteristics, using the NBA season schedule to track referee work load. Table 3 shows only results for days off between games as a proxy for fatigue. Equation (1) includes these other fatigue proxy variables including the length of the fourth quarter in actual clock time, pace of the game in the fourth quarter, and game tip off time, as well as whether the game was nationally televised and attendance. Parameter estimates for these other variables are not reported on Table 3 since they are not statistically different from zero.

Our variables of interest are the number of days off between games and the distance traveled between games, proxy variables for fatigue. Days Off simply reflects the average amount of time that elapsed between games worked by referee crew members, which reflects time to recover from the physical and mental exertion required to officiate an NBA game. The coefficient estimate for the number of days off is significantly different from zero and indicates that the more recovery time members of a crew have between games, the more accurate their calls in the last two minutes of close games.

Results in columns 1 and 2 in Table 3 use the mean days of reset for crew members as fatigue proxies and columns 3 and 4 use the median. Again, we can identify fatigue proxy for each referee but cannot always identify which call each referee made, because L2Ms do not always identify the referee who made each evaluated call. Therefore, we need to use an average measure of fatigue for the referee crew. We choose mean and median and the results are robust to this. We continue to use mean from here since it exhibits slightly more variability across games, and thus more information than the median. Columns 1 and 3 use the total number of correct calls and columns 2 and 4 the percent of correct calls as referee accuracy.

The results of all four regression models agree with one another. In all four, more rested referee crews make better decisions in the last two minutes of close games, controlling for other factors that might affect referee decision making. Again, very few of the games with L2M reports analyzed on Table 3 were unexpected upsets, which we assume generate strong emotional cues triggering domestic violence. Since the results on Table 3 establish a clear link between referee crew fatigue and accuracy, we include referee fatigue proxy variables directly in the empirical models explaining variation in domestic violence to identify games where referees might have made errors that led to unexpected losses. 
Table 3: Effect of Fatigue on Referee Correctness

\begin{tabular}{lcccc}
\hline \hline & \multicolumn{4}{c}{ Dependent variable: } \\
\cline { 2 - 5 } & \# of CC & \% CC & \# of CC & $\%$ CC \\
& $(1)$ & $(2)$ & $(3)$ & $(4)$ \\
\hline Total Calls & $0.893^{* * *}$ & & $0.893^{* * *}$ & \\
& $(0.027)$ & & $(0.027)$ & \\
& & & & \\
Days Off (mean) & $0.019^{* *}$ & $0.002^{* * *}$ & & \\
& $(0.008)$ & $(0.001)$ & & \\
Days Off (median) & & & $0.020^{* *}$ & $0.002^{* *}$ \\
& & & $(0.009)$ & $(0.001)$ \\
& & & & \\
\hline Observations & 1,365 & 1,365 & 1,365 & 1,365 \\
$\mathrm{R}^{2}$ & 0.950 & 0.060 & 0.950 & 0.062 \\
Adjusted $\mathrm{R}^{2}$ & 0.949 & 0.051 & 0.949 & 0.052 \\
\hline \hline
\end{tabular}

Note:

${ }^{*} \mathrm{p}<0.1 ;{ }^{* *} \mathrm{p}<0.05 ;{ }^{* * *} \mathrm{p}<0.01$

All models contain season $\times$ playoff fixed effects to control for differences in regular season and post-season correctness. All four models exclude Shelby county and control for distance traveled by the referee crew. We do not report the statistically not different coefficients on distance traveled. Finally, all models control for game tip off time, length of the last two minutes of play, pace of play in the fourth quarter, attendance, and if the game was nationally televised though all are not statistically different from zero.

\subsection{Unexpected Losses and Family Violence}

In Table 4, we adopt and extend the empirical work in Card and Dahl (2011) to examine the effect of unexpected losses in NBA games on family violence. The results on Table 4 come from Equation (3). We estimate the models for two different sub-samples of games: weekday games and weekend games. Since nearly all NFL games occur on Sunday, we separate the sample into weekend and weekday games to make our results more comparable to Card and Dahl (2011). The three most common days for NBA games are Saturday, Sunday and Thursday.

These regressions use daily observations of family violence in a county where an NBA game was played during the hours from $6 \mathrm{PM}$ to $6 \mathrm{AM}$ during the NBA regular season as the dependent variable, a measure of interpersonal violence (IPV). We focus only on regular season NBA games, not the playoffs. Columns (1) and (2) contain results for weekday games and columns (3) and (4) for weekend games. 
Table 4: Effect of Unexpected Emotional Shocks from NBA Games on At Home Intimate-Partner Violence

\begin{tabular}{|c|c|c|c|c|}
\hline & \multicolumn{4}{|c|}{ Dependent variable: } \\
\hline & \multicolumn{4}{|c|}{ IPV } \\
\hline & \multicolumn{2}{|c|}{ Weekdays } & \multicolumn{2}{|c|}{ Weekends } \\
\hline & $(1)$ & $(2)$ & $(3)$ & $(4)$ \\
\hline Predicted Win & $\begin{array}{c}-0.302^{*} \\
(0.171)\end{array}$ & $\begin{array}{l}-0.192 \\
(0.136)\end{array}$ & $\begin{array}{c}0.046 \\
(0.241)\end{array}$ & $\begin{array}{l}-0.032 \\
(0.208)\end{array}$ \\
\hline Predicted Loss & $\begin{array}{l}-0.171 \\
(0.202)\end{array}$ & $\begin{array}{l}-0.112 \\
(0.130)\end{array}$ & $\begin{array}{c}0.050 \\
(0.255)\end{array}$ & $\begin{array}{l}-0.098 \\
(0.204)\end{array}$ \\
\hline Predicted Close & $\begin{array}{c}-0.217^{*} \\
(0.129)\end{array}$ & $\begin{array}{c}-0.166^{*} \\
(0.092)\end{array}$ & $\begin{array}{c}0.109 \\
(0.247)\end{array}$ & $\begin{array}{l}-0.027 \\
(0.181)\end{array}$ \\
\hline Predicted Win : Loss & $\begin{array}{c}0.050 \\
(0.086)\end{array}$ & $\begin{array}{c}0.007 \\
(0.125)\end{array}$ & $\begin{array}{l}0.157^{\text {** }} \\
(0.067)\end{array}$ & $\begin{array}{c}0.222^{* * *} \\
(0.054)\end{array}$ \\
\hline Predicted Loss : Win & $\begin{array}{l}-0.061 \\
(0.113)\end{array}$ & $\begin{array}{l}-0.106 \\
(0.108)\end{array}$ & $\begin{array}{c}0.022 \\
(0.099)\end{array}$ & $\begin{array}{c}0.022 \\
(0.095)\end{array}$ \\
\hline Predicted Close : Loss & $\begin{array}{l}-0.027 \\
(0.054)\end{array}$ & $\begin{array}{l}-0.034 \\
(0.043)\end{array}$ & $\begin{array}{l}-0.050 \\
(0.053)\end{array}$ & $\begin{array}{l}-0.023 \\
(0.048)\end{array}$ \\
\hline $\mathrm{N}$ & 6,568 & 6,568 & 2,584 & 2,584 \\
\hline Team FE & Yes & No & Yes & No \\
\hline Month FE & Yes & No & Yes & No \\
\hline Year FE & Yes & No & Yes & No \\
\hline Team by Season FE & No & Yes & No & Yes \\
\hline
\end{tabular}

All regressions in this table use weekday and holiday fixed effects along with controls for predicted win, loss and close like in Card and Dahl (2011). We also include controls for tipoff time and whether a game was televised nationally. We also cluster our standard errors at the county/team level, remaining consistent with Card and Dahl (2011).

Our regressions reveal similar results for the NBA as previously found for the NFL: upset losses significantly increase domestic violence incidents, however only for NBA games played on weekends. The key explanatory variables on Table 4 identify expected game outcomes based on the point spread on each game (expected wins, losses, and games expected to be close), and interaction variables with actual game outcomes. The key explanatory variable on Table 4 interacts the predicted win variable with an indicator variable for actual losses. Following the existing literature, we posit that these outcomes generate strong emotional cues that generate domestic violence.

From columns (3) and (4), the parameter estimates on the expected win-actual loss indicator variable is positive and significant for weekend NBA games only. Domestic violence incidents increase on weekend evenings in counties where the local NBA team experienced an unexpected loss, other things constant. Column (3) reflects models including year, month, day of week and county fixed effect: 9 . Column (4) reflects

\footnotetext{
${ }^{9}$ We limit our analysis to counties with only one NBA team, which means county fixed effects are the same as team fixed
} 
models including county by NBA season, month, and day of week fixed effects.

We control for NBA season rather than year because a team's ability and/or expectations can vary dramatically across different seasons, which could affect how fans process upset losses. Year fixed effects would fail to capture this since each NBA season contains two calendar years. An example of a situation like this occurred to fans of the Cleveland Cavaliers in 2013. During the 2013-2014 season, LeBron James returned to the team, which tripled the number of nationally televised Cavaliers games from about 10 to about 35. Figure 12 of the Appendix illustrates this increase in nationally televised games.

We next investigate referee accuracy as the mechanism for the results on Table 4 . As discussed above, the effects of referee accuracy in unexpected losses could trigger a violent outburst, as fans can identify blame for the unexpected loss and project this onto their victims. To identify this mechanism, we combine our results regarding referee fatigue with that of increased family violence after unexpected losses in Table 5 Specifically, we estimate a similar regression, but allow the upset loss coefficient to vary systematically with referee crew rest, measured by the average days off for the crew.

Table 5: Effect of Referee Fatigue in Unexpected Losses on At Home Intimate-Partner Violence

\begin{tabular}{|c|c|c|c|c|}
\hline & \multicolumn{4}{|c|}{ Dependent variable: } \\
\hline & \multicolumn{4}{|c|}{ IPV } \\
\hline & $(1)$ & $(2)$ & $(3)$ & $(4)$ \\
\hline Predicted Win : Loss & $\begin{array}{c}0.708^{* * *} \\
(0.114)\end{array}$ & $\begin{array}{c}0.527^{* * *} \\
(0.167)\end{array}$ & & \\
\hline Predicted Win : Loss : Days Off & $\begin{array}{c}-0.199^{* * *} \\
(0.032)\end{array}$ & $\begin{array}{c}-0.127^{* * *} \\
(0.042)\end{array}$ & & \\
\hline Predicted Win : Loss : "High" Rest & & & $\begin{array}{l}-0.104 \\
(0.223)\end{array}$ & $\begin{array}{c}0.104 \\
(0.249)\end{array}$ \\
\hline Predicted Win : Loss : "Medium" Rest & & & $\begin{array}{l}-0.106 \\
(0.202)\end{array}$ & $\begin{array}{l}-0.053 \\
(0.150)\end{array}$ \\
\hline Predicted Win : Loss : "Low" Rest & & & $\begin{array}{c}0.473^{* * *} \\
(0.105)\end{array}$ & $\begin{array}{c}0.398^{* * *} \\
(0.137)\end{array}$ \\
\hline $\mathrm{N}$ & 2,560 & 2,560 & 2,560 & 2,560 \\
\hline Team FE & Yes & No & Yes & No \\
\hline Month FE & Yes & No & Yes & No \\
\hline Year FE & Yes & No & Yes & No \\
\hline Team by Season FE & No & Yes & No & Yes \\
\hline
\end{tabular}

Note:

${ }^{*} \mathrm{p}<0.1 ;{ }^{* *} \mathrm{p}<0.05 ;{ }^{* * *} \mathrm{p}<0.01$

All regressions in this table use weekday and holiday fixed effects along with controls for predicted win, loss and close like in Card and Dahl (2011). We also include controls for tipoff time and whether a game was televised nationally. In addition, we include a full set of interactions with fatigue \& game prediction/outcome variables. We also cluster our standard errors at the county/team level, remaining consistent with Card and Dahl (2011).

effects 
In Table 5 we interact various levels of rest between games with the variables identifying unexpected NBA game outcomes. We interact the unexpected loss dummy variable and a continuous days off measure in columns (1) and (2). The results show a significant and positive effect of upset losses on family violence, but this is mitigated by the average number of days of rest for the referee crew officiating the game. Since rest is positively correlated with correct referee decisions, we interpret this result reflecting referee decision making. Because more rest between games increases referee accuracy, the emotional cue generated by unexpected losses falls when the referee crew makes more correct calls, because the instigator of domestic violence incidents cannot blame the upset loss on the referees. This, in turn, decreases family violence incidents triggered by the unexpected loss. An extrapolation of these results would suggest that if referee crews rested an average of 3.5 days the effect of an upset loss on family violence would be zero. This is found by dividing the two coefficients in Column 2.

Columns (3) and (4) in Table 5 divide the referee fatigue measure into bins for high, medium and low rest crew indicator variables. We choose this specification to reflect a non-linear relationship between fatigue and family violence attributable to unexpected losses. Games are split up by dividing the rest variable distribution into thirds at the $33^{\text {rd }}$ and $67^{\text {th }}$ percentiles of the distribution. We consider referee crews with less than 2.33 days of rest as low rest, and consider crews with more than 3 days of rest as high rest games, and crews with $2.33,2.66$ or 3 days of rest are considered medium rest.

Using this specification, we find the effect of unexpected losses on family violence occurs only in games with low referee rest, or in other words high referee crew fatigue. Again, referees likely make more incorrect calls in games with high referee fatigue, which can amplify the negative emotional cue generated by the upset loss because of the presence of a scapegoat, incompetent referees, on which to blame the unexpected loss. In the mind of a domestic abuser, the home team, with which the abuser identifies, performed admirably, but the incompetent referees made the team lose a game they were expected to win.

The results of these regressions suggest heterogeneity in upset losses. Upset losses with fatigued referees seem to generate more domestic violence relative to upset losses with rested referees. We hypothesize that this is due to fatigue generating more errors, which fans are then able to blame on others. This assumes that fan loyalty affects individual decision-making. Results in Lindo et al. (2012) supports this role of fan loyalty by providing evidence that college achievement decreases, specifically for men, with the success of collegiate sports programs.

\section{Robustness Checks}

Our main results suggest that when fans are able to place blame for an unexpected loss on referees, athome family violence increases. We posit that this expressive violence is triggered by increased referee errors due to fatigue in unexpected losses. However, since we deviate from the literature by using larger cutoff values to identify expected wins and losses from point spread data, we test the sensitivity of our estimates to these cutoffs.

\subsection{Varying Point Spreads}

A major difference between this paper and Card and Dahl (2011) is the definition of predicted wins and losses. This difference can be attributed to to several factors. First, there are inherent differences in scoring in the two sports in question (NBA Basketball and NFL Football). Second, Card and Dahl (2011) use a symmetric point spread of -3 for predicted wins and +3 for predicted losses, while we select the cutoff point 
spreads based on the averages of the positive (expected loss) and negative (expected win) point spreads. We reestimate the models with varying point spread thresholds from -3 to -10 for predicted wins and +2 to +8 for predicted losses in order to check the sensitivity of the results to the selected point spread. We increment the point spread threshold by .5 point increments, as shown in the point spread frequency distribution in Figure 2. The long solid vertical line depicts the original threshold values, and the dashed lines show what changing the threshold point spread for expected wins and losses looks like. When we change the point spread threshold, we move both lines closer (farther) together (apart), which we consider a negative (positive) adjustment.

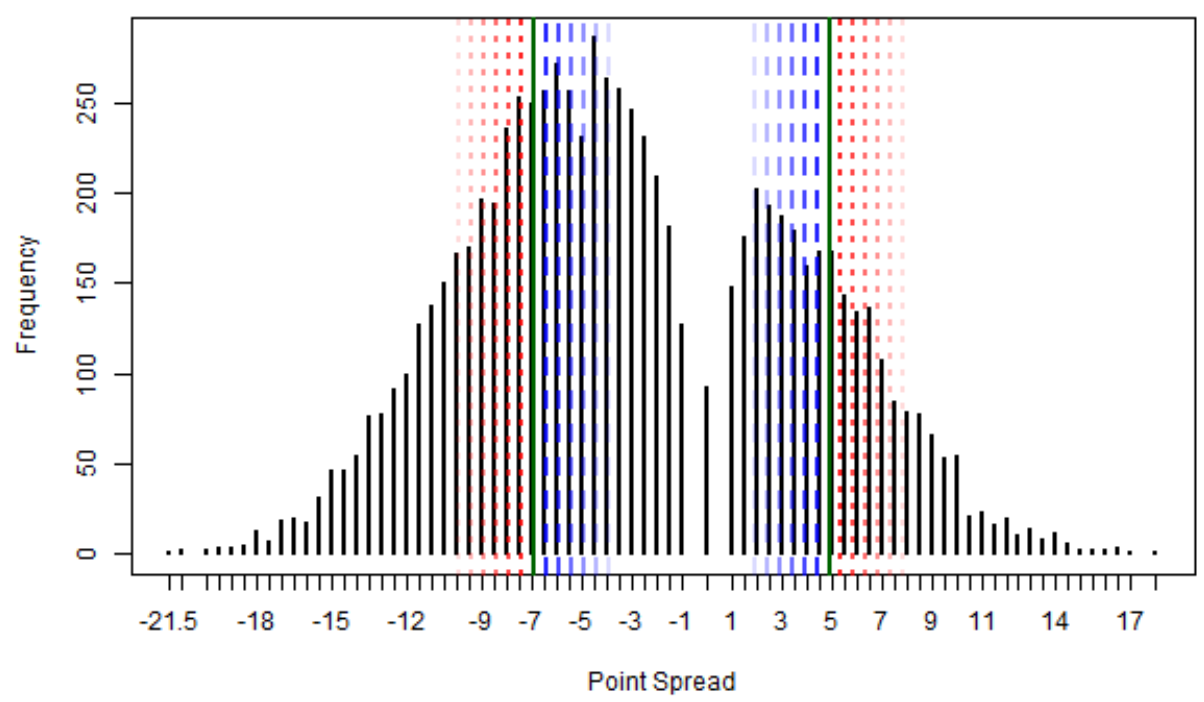

Figure 2: Varied Point Spread

In Figure 3 , we present the coefficient estimates on the unexpected loss indicator reflecting the impact on domestic violence given zero referee rest in a game. A negative value on the $\mathrm{x}$ axis means a inward shift of the point spread threshold identifying expected losses and wins, meaning the two cutoffs move closer together. Positive values suggest larger upset losses. The left panel on Figure 3 reflects models including county and season effects and the right panel reflects models including county by season fixed effects.

Larger upset losses, that is losses when the home team was a stronger and stronger favorite, generate much larger increases in domestic violence. It is also the case that our point spread cutoff values, chosen based on the observed distributions of positive and negative point spreads, appears to be an inflection point for this effect. Figure 4 displays the estimates for our coefficient of interest, the indicator variable for unexpected losses interacted with referee fatigue, and shows a similar pattern to Figure 3 . Our results remain robust to alternative point spread threshold values for expected wins and losses. 

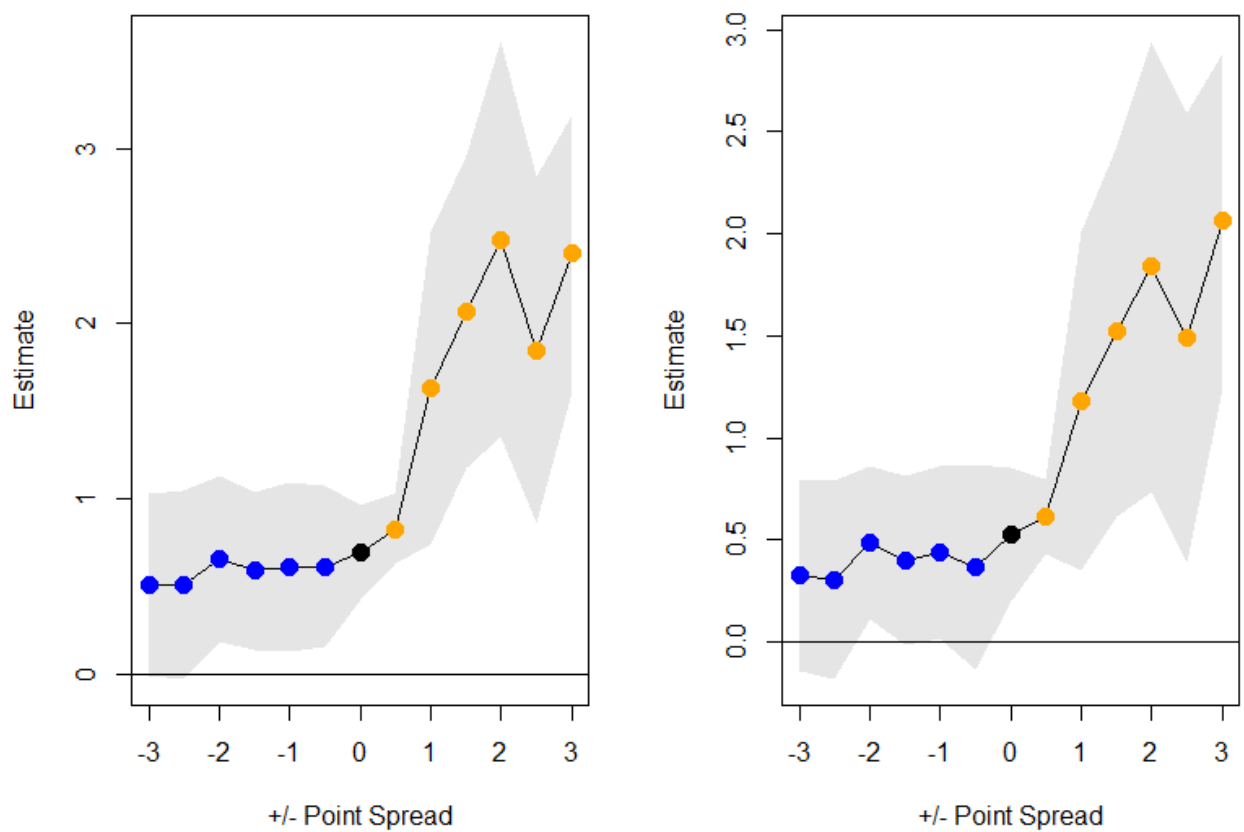

Figure 3: Upset Loss Coefficient
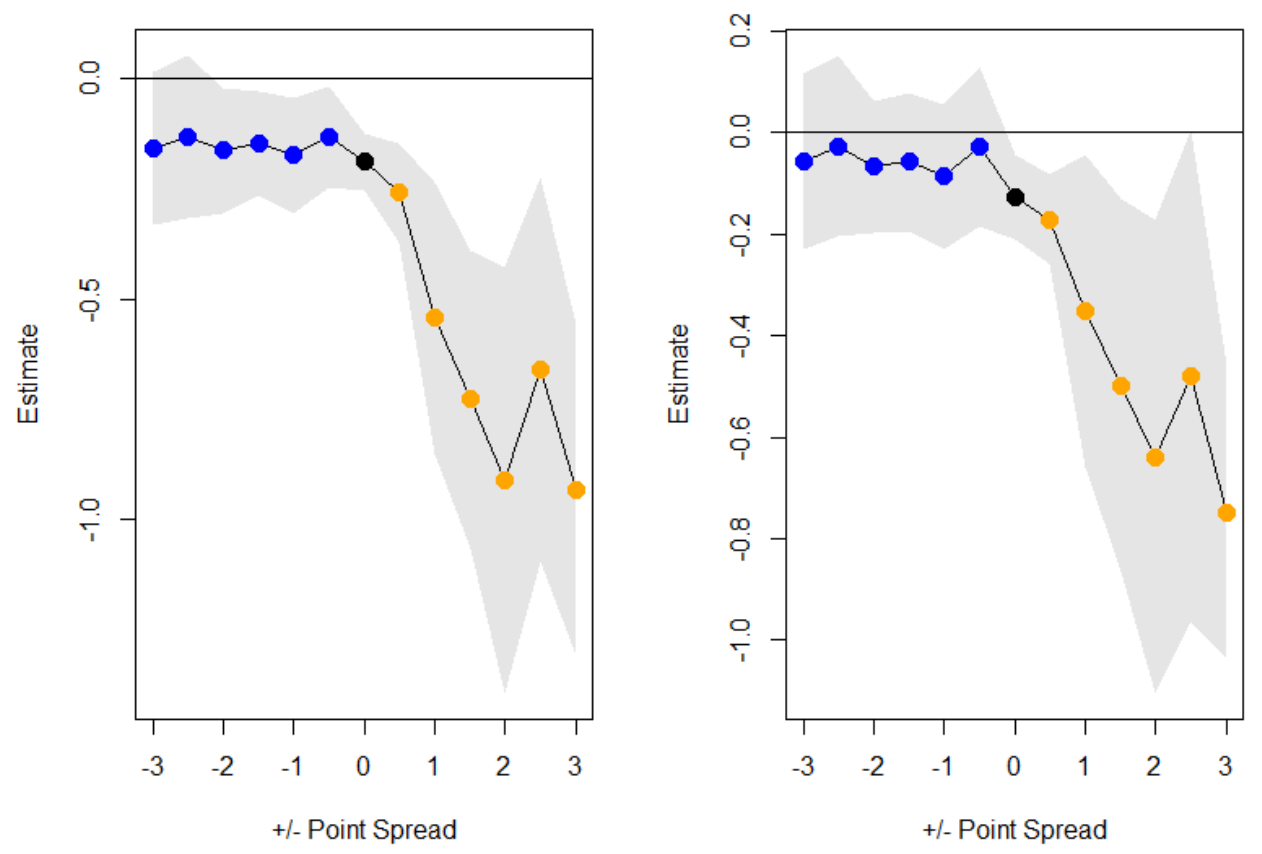

Figure 4: Upset Loss : Days Off Coefficient 


\section{$5.2 \quad$ Using L2M Correctness}

We use referee fatigue to proxy for referee call correctness in the full sample of games. Including fatigue proxy variables allows us to identify referee quality in ways that the L2M data fail to do. Using a fatigue proxy and not actual call correctness provides two empirical benefits. First, the proportion of unexpected losses in L2M games is not the same as the proportion of unexpected losses in all games. Using only games with L2M reports generates a non-random subset of games which may not be representative. Second, fatigue is likely to better capture referee performance over all 48 minutes of the game, and not only the last two minutes. Further, referee fatigue, but not referee correctness, can be more easily targeted by NBA league policy and other professional sports.

For completeness, we estimate the parameters of Equation (3) explaining variation in the number of intimate partner violence incidents on a small subsample of NBA games with L2M reports played in the 8 counties in our sample. Table 6 contains the results. From Table 6, a negative relationship exists between referee correctness in NBA games and intimate partner violence during evening hours after games were played in counties where the games were played. Less domestic violence occurs in games where NBA referees made more correct calls in the last two minutes of play, based on the L2M reports. This result supports the results using referee fatigue as a proxy for referee decision making.

Table 6: Effect of L2M Referee Correctness on Intimate Partner Violence

\begin{tabular}{lcc}
\hline \hline & \multicolumn{2}{c}{ Dependent variable: } \\
\cline { 2 - 3 } & \multicolumn{2}{c}{ IPV } \\
& $(1)$ & $(2)$ \\
\hline \% Correct in L2M & -0.156 & $-0.679^{*}$ \\
& $(0.136)$ & $(0.388)$ \\
\hline $\mathrm{N}$ & 694 & 694 \\
Team FE & Yes & No \\
Month FE & Yes & No \\
Year FE & Yes & No \\
Team by Season FE & No & Yes \\
Weekday FE & Yes & Yes \\
Holiday FE & Yes & Yes \\
\hline \hline Note: & ${ }^{*} \mathrm{p}<0.1 ;{ }^{* *} \mathrm{p}<0.05 ;{ }^{* * *} \mathrm{p}<0.01$
\end{tabular}

\subsection{Days of The Week Sample}

In our main analysis, we extend the results in Card and Dahl (2011) following their empirical approach as closely as possible using data from NBA games by only using games played on weekends. However, we can test the external validity of this identification by estimating models using other sets of weekdays. For brevity, we only include results from regression models that use team by season fixed effects.

We test our specification on three different subsets of days of the week. First, we use all games in the first two columns. Next, in columns 3 and 4, we use only games played on weekdays. Finally, we redefine weekends to include Thursdays and Fridays as well as Saturday and Sunday. The key result persists across these different specifications. While we do not find significance for upset losses alone in Table 4 , we do find evidence that upset losses affect intimate partner violence once we include fatigue. 
Table 7: Varying the Sample of Days

\begin{tabular}{|c|c|c|c|c|c|c|}
\hline & \multicolumn{6}{|c|}{ Dependent variable: } \\
\hline & \multicolumn{6}{|c|}{ IPV } \\
\hline & \multicolumn{2}{|c|}{ All Days } & \multicolumn{2}{|c|}{ Weekdays } & \multicolumn{2}{|c|}{ Extended Weekends } \\
\hline & $(1)$ & $(2)$ & $(3)$ & $(4)$ & $(5)$ & $(6)$ \\
\hline Predicted Win : Loss & $\begin{array}{c}0.359^{* * *} \\
(0.128)\end{array}$ & & $\begin{array}{c}0.417^{* * *} \\
(0.144)\end{array}$ & & $\begin{array}{c}0.313^{* * *} \\
(0.105)\end{array}$ & \\
\hline Predicted Win : Loss : Days Off & $\begin{array}{c}-0.102^{*} \\
(0.057)\end{array}$ & & $\begin{array}{c}-0.145^{* *} \\
(0.069)\end{array}$ & & $\begin{array}{c}-0.086^{* * *} \\
(0.031)\end{array}$ & \\
\hline Predicted Win : Loss : "High" Rest & & $\begin{array}{c}0.027 \\
(0.081)\end{array}$ & & $\begin{array}{l}-0.043 \\
(0.146)\end{array}$ & & $\begin{array}{c}0.090 \\
(0.079)\end{array}$ \\
\hline Predicted Win : Loss : "Medium" Rest & & $\begin{array}{l}-0.173 \\
(0.168)\end{array}$ & & $\begin{array}{l}-0.196 \\
(0.243)\end{array}$ & & $\begin{array}{l}-0.315 \\
(0.285)\end{array}$ \\
\hline Predicted Win : Loss : "Low" Rest & & $\begin{array}{c}0.242^{* * *} \\
(0.068)\end{array}$ & & $\begin{array}{c}0.175^{* * *} \\
(0.060)\end{array}$ & & $\begin{array}{c}0.293^{* * *} \\
(0.088)\end{array}$ \\
\hline $\mathrm{N}$ & 9,031 & 9,031 & 6,471 & 6,471 & 5,112 & 5,112 \\
\hline Team by Season FE & Yes & Yes & Yes & Yes & Yes & Yes \\
\hline Weekday FE & Yes & Yes & Yes & Yes & Yes & Yes \\
\hline Holiday FE & Yes & Yes & Yes & Yes & Yes & Yes \\
\hline
\end{tabular}

All regressions in this table use weekday and holiday fixed effects along with controls for predicted win, loss and close like in Card and Dahl (2011). We also include controls for tipoff time, whether a game was televised nationally, and team by season fixed effects. We also cluster our standard errors at the county/team level, remaining consistent with Card and Dahl (2011).

\section{Conclusion}

Evidence shows that male-on-female family violence increases after unexpected losses by the local sports team. These results offer compelling evidence that family violence increases in cities where home teams were predicted to win according the Las Vegas point spread, but actually lose the game. Exploration of the NBA L2M allows us to explore the role of referee decisions, in terms of referee fatigue, may affect the negative emotional cue generated by unexpected losses, and in turn family violence. This objective evaluation of NBA referee performance provides a basis for quantifying correctness in NBA officiating. We measure the effect of rest on referee accuracy given variables like travel and days rest between games officiated. We find that variables that measure rest between games in terms of time (e.g. extra days off, gaining hours by traversing time zones) explains referee correctness.

We analyze National Incident Based Reporting System (NIBRS) data from counties that are home to 8 NBA teams, focusing on the effect of unexpected wins on reported at-home, male-to-female family violence incidents. We find an increase in at-home, male-to-female family violence after unexpected losses.

We combine results from our analyses of referee fatigue and increased family violence after unexpected 
losses to identify mechanisms that may lead to increased outbursts of family violence. After analyzing the interaction between referee accuracy and unexpected losses, we find that as referees are more fatigued, family violence caused by unexpected losses increases. We interpret this result as, when the salience of a loss becomes more clear, in that it is due not to performance of the local team but instead to good referee decisions, the likelihood of emotional outbursts decreases. Our results persist in analysis of family violence incidents given betting market expectations. Results indicate that our effect concentrates in games where referees are fatigued and home teams were more heavily favored to win the game.

These results indicate that the link between unexpected losses and family violence is more pervasive than previously thought, as we identify these effects in a sport other than the National Football League. Identifying referee accuracy due to a lack of between-game rest speaks directly to ongoing debate in both the NBA and college basketball. National Collegiate Athletic Association referees work more often and travel further distances throughout a season than NBA referees. Coaches across the NCAA complain about the heavy workloads of college basketball referees and the effect it has on the game ${ }^{10}$ Discussion of shorter games and shorter overall seasons continue between the NBA Player's Union and the league's board of governors, as players and teams recognize the value of between-game rest 11 While leagues and team owners fear the lost revenue the comes with shortening games or schedules, more rest for players and referees may be what is best for the health and safety of the league and its fans.

\footnotetext{
${ }^{10}$ The Associated Press, "N.C.A.A. Referees' Workloads Attract Comment and Scrutiny," New York Times, March 2, 2013

${ }^{11}$ Reynolds, Tim, "Report: NBA, teams, players union discuss shortening season," NBA.com, Nov 23, 2019
} 


\section{References}

Ali, P. A., Dhingra, K., and McGarry, J. (2016). A literature review of intimate partner violence and its classifications. Aggression and Violent Behavior, 31:16-25.

Babcock, J. C., Costa, D. M., Green, C. E., and Eckhardt, C. I. (2004). What situations induce intimate partner violence? a reliability and validity study of the proximal antecedents to violent episodes (pave) scale. Journal of Family Psychology, 18(3):433.

Bobonis, G. J., González-Brenes, M., and Castro, R. (2013). Public transfers and domestic violence: The roles of private information and spousal control. American Economic Journal: Economic Policy, 5(1):179205.

Breiding, M. J., Smith, S. G., Basile, K. C., Walters, M. L., Chen, J., and Merrick, M. T. (2015). Prevalence and characteristics of sexual violence, stalking, and intimate partner violence victimization-national intimate partner and sexual violence survey, united states, 2011. American Journal of Public Health, 105(4):e11-e12.

Card, D. and Dahl, G. B. (2011). Family violence and football: The effect of unexpected emotional cues on violent behavior. The Quarterly Journal of Economics, 126(1):103-143.

Carrell, S. E., Hoekstra, M., and Kuka, E. (2018). The long-run effects of disruptive peers. American Economic Review, 108(11):3377-3415.

Dowling, N., Suomi, A., Jackson, A., Lavis, T., Patford, J., Cockman, S., Thomas, S., Bellringer, M., KoziolMclain, J., Battersby, M., et al. (2016). Problem gambling and intimate partner violence: A systematic review and meta-analysis. Trauma, Violence, \& Abuse, 17(1):43-61.

Eren, O. and Mocan, N. (2018). Emotional judges and unlucky juveniles. American Economic Journal: Applied Economics, 10(3):171-205.

Feddersen, A., Humphreys, B. R., and Soebbing, B. P. (2018). Sentiment bias in national basketball association betting. Journal of Sports Economics, 19(4):455-472.

Ge, Q. (2018). Sports sentiment and tipping behavior. Journal of Economic Behavior E Organization, 145:95-113.

Greene, C. A., Chan, G., McCarthy, K. J., Wakschlag, L. S., and Briggs-Gowan, M. J. (2018). Psychological and physical intimate partner violence and young children's mental health: The role of maternal posttraumatic stress symptoms and parenting behaviors. Child Abuse $\&$ Neglect, 77:168-179.

Harper, L. D., West, D. J., Stevenson, E., and Russell, M. (2014). Technical performance reduces during the extra-time period of professional soccer match-play. PloS one, 9(10).

Hidrobo, M., Peterman, A., and Heise, L. (2016). The effect of cash, vouchers, and food transfers on intimate partner violence: evidence from a randomized experiment in northern ecuador. American Economic Journal: Applied Economics, 8(3):284-303.

Hsu, L.-C. (2017). The timing of welfare payments and intimate partner violence. Economic Inquiry, 55(2):1017-1031. 
Huck, J. R. (2018). Taking a beating on the stock market: Crime and stock returns. SSRN Working Paper \#244804\%.

Klostermann, K. C. and Fals-Stewart, W. (2006). Intimate partner violence and alcohol use: Exploring the role of drinking in partner violence and its implications for intervention. Aggression and Violent Behavior, 11(6):587-597.

Lindo, J. M., Swensen, I. D., and Waddell, G. R. (2012). Are big-time sports a threat to student achievement? American Economic Journal: Applied Economics, 4(4):254-74.

Marshall, A. D., Robinson, L. R., and Azar, S. T. (2011). Cognitive and emotional contributors to intimate partner violence perpetration following trauma. Journal of Traumatic Stress, 24(5):586-590.

Martin, K. R. and Garcia, L. (2011). Unintended pregnancy and intimate partner violence before and during pregnancy among latina women in los angeles, california. Journal of Interpersonal Violence, 26(6):11571175.

McCormack, P. D., Pattavina, A., and Tracy, P. E. (2017). Assessing the coverage and representativeness of the national incident-based reporting system. Crime $\mathcal{E}$ Delinquency, 63(4):493-516.

Peterson, C., Kearns, M. C., McIntosh, W. L., Estefan, L. F., Nicolaidis, C., McCollister, K. E., Gordon, A., and Florence, C. (2018). Lifetime economic burden of intimate partner violence among us adults. American Journal of Preventive Medicine, 55(4):433-444.

Potoski, M. and Urbatsch, R. (2017). Entertainment and the opportunity cost of civic participation: Monday night football game quality suppresses turnout in us elections. The Journal of Politics, 79(2):424-438.

Sarmiento-Barbieri, I., Ge, Q., and Schneider, R. (2018). Emotional cues and crime: Spatial and temporal evidence from Brazilian soccer games. SSRN Working Paper \#3289286.

Schenk, K., Bizzini, M., and Gatterer, H. (2018). Exercise physiology and nutritional perspectives of elite soccer refereeing. Scandinavian Journal of Medicine 83 Science in Sports, 28(3):782-793.

Schwartz, B. and Barsky, S. F. (1977). The home advantage. Social forces, 55(3):641-661.

Tur-Prats, A. (2019). Family types and intimate partner violence: A historical perspective. Review of Economics and Statistics, 101(5):878-891.

Weston, M., Bird, S., Helsen, W., Nevill, A., and Castagna, C. (2006). The effect of match standard and referee experience on the objective and subjective match workload of English Premier League referees. Journal of Science and Medicine in Sport, 9(3):256-262. 


\section{Appendix}

\subsection{Betting Market Expectations and Unexpected Game Outcomes}

The main results in the paper depend critically on identifying games with unexpected outcomes, which, by assumption, generate larger emotional cues than games with expected outcomes. The results above use the point spread on each game and the actual game outcome to identify games with unexpected outcomes, using the approach of Card and Dahl (2011). However, other approaches can be used to identify games with unexpected outcomes that make use of more data from NBA betting markets. This section develops and alternative approach using both point spreads and money line odds for NBA games.

Consider a recent NBA basketball game between the Los Angeles Lakers and the Houston Rockets ${ }^{12}$ The game is played in Los Angeles who is favored to win by 6. In gambling terminology, this is the point spread. A bet on the Lakers wins if and only if they win by more than 6 points. A bet on the Rockets wins if either the Rockets win, or the Lakers win by less than 6 points ${ }^{13}$ The payoff consequences to these bets is -110 . This means that a gambler must risk $\$ 110$ to receive a profit of $\$ 100$. The extra $\$ 10$, known as the "vig" is the profit margin of the bookmaker.

In addition, a gambler can, instead, place what is known as a "money line" bet on the Lakers. This bet wins if the Lakers win, regardless of the margin of victory. Similarly, a gambler can make a money line bet on the Rockets. They must win for this gamble to be profitable. Since the betting market expects the Lakers to win, a gambler must risk more to get the payoff. Similarly, a gambler who is willing to bet on the Rockets to win when they are expected to lose, must receive a greater profit if the win happens. For this game, the money line bet was Lakers -250 and Rockets +210 . The former means that a gambler must put up $\$ 250$ for the chance to earn a $\$ 100$ profit. The latter implies that if the gambler risks $\$ 100$, then s/he can win $\$ 210$.

These money line bets can be used to estimate the market's expectations on the probability each team will win the game. For example, consider a money line bet on the Los Angeles Lakers. One can ask what is the probability the Lakers will win the game that would result in this being a "fair" bet. That is, if a gambler is a risk-neutral, expected-wealth maximizer what is the probability of victory that would make the gambler indifferent between betting on the Lakers and not?

A bet on the Lakers has an expected payoff of $\mathrm{E} \pi$ (Lakers) $=350 P_{\text {lakers }}+0\left(1-P_{\text {lakers }}\right)$ where $P_{\text {lakers }}$ is the probability the Lakers will win the game. If it happens the gambler making this money line bet will end up with a wealth level of $\$ 350$ - the $\$ 250$ risked and the $\$ 100$ profit earned. Alternatively, if the gambler does not bet on the Lakers, then she keeps the $\$ 250$. Thus, the expected probability of a Lakers victory is

$$
P_{\text {lakers }}=\frac{250}{350}=0.7143 \text {. }
$$

Alternatively, a bet on the Rockets to win generates an expected payoff of $\mathrm{E} \pi$ (Rockets) $=310 P_{\text {rockets }}+$ $0\left(1-P_{\text {rockets }}\right)$ for a risk-neutral, expected-wealth maximizer. Not betting on the Rockets leaves the gambler with the $\$ 100 \mathrm{~s} /$ he would have risk. Hence, the expected probability of a Rockets victory is

$$
P_{\text {rockets }}=\frac{100}{310}=0.3226 \text {. }
$$

Notice that the two probabilities sum to a number greater than one. This, again, represents the profit margin of the book maker. Thus, commonly in the literature, the midpoint is used

\footnotetext{
${ }^{12}$ This example comes from the actual betting odds of a game between the Los Angeles Lakers and Houston Rockets played on February 6, 2020.

${ }^{13}$ A Lakers win by exactly 6 points is a push.
} 


$$
P_{\text {lakers }}^{\prime}=\frac{P_{\text {lakers }}+\left(1-P_{\text {rockets }}\right)}{2}=0.6959 .
$$

In other words the gambling market expects the Lakers to win with a $70 \%$ probability.

Our insight is that the point spread and money line bets provide two points on the distribution that captures the market's expectations of what will happen in the game. Thinking of the expectations on the home team's margin of victory. The beliefs can be thought of as a distribution function with its mean at 6 (the point spread) and the probability mass to the right of the zero threshold of approximately $70 \%$ (i.e., $1-F(0)=0.6959)$.

If we make the assumption that the betting market's expectations follow a normal distribution, then with these two measurements the standard deviation of the market's expectations can be estimated. That is, we can find $\sigma$ where

$$
F(0 ; \mu=6, \sigma)=0.3061
$$

and $F(\cdot)$ is the cumulative normal distribution. To complete this example, the estimated standard deviation is 11.835. Hence, the expectations on the Lakers's success in the game against the Rockets can be depicted as follows

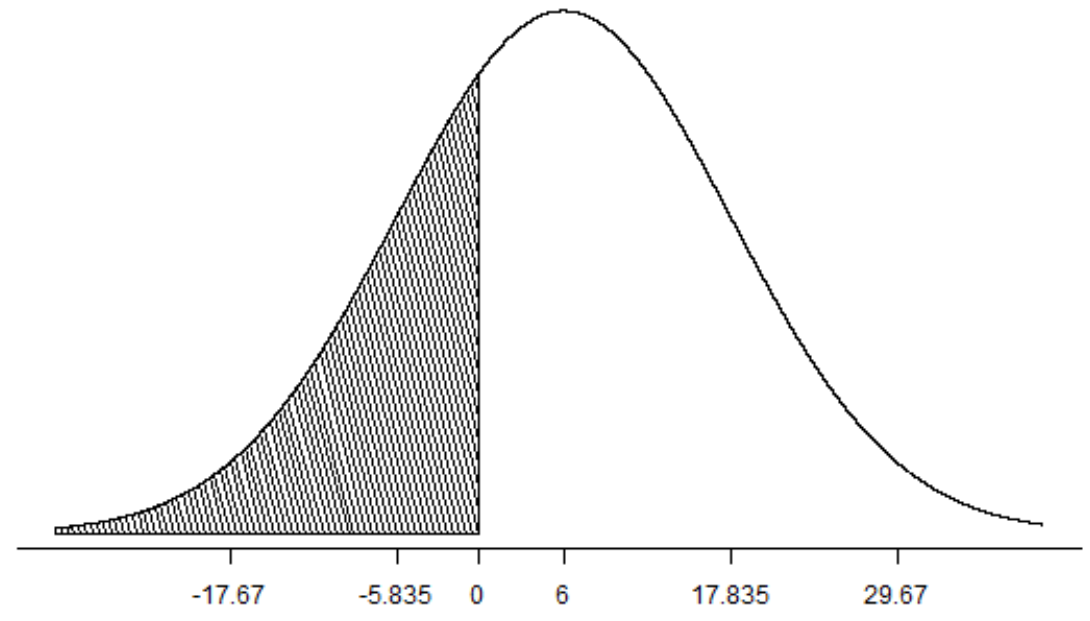

Instead, if another game (with a 6 point spread) is characterized by more certainty in the gambling market on the outcome, so that $\sigma=6$, cutting the standard deviation in half, then the probability the favored team wins the game would be 0.8413 . This would arise if the money line bet on the favored team was -530 (instead of the Lakers's -250).

Following this framework, we can not only identify the expected margin of victory (so that a surprise loss can be recorded), but we can measure the certainty of those expectations. For example, if there is another game with a point spread of 6 , but with a larger standard deviation from the money line bet, this tells us that this second game has more uncertainty in the gambling market than the Lakers-Rockets game, holding constant the mean margin of victory. This will allow us to disentangle unexpected losses in games where gamblers went into that game more uncertain of the outcome, from games with an unexpected loss where 
gamblers came in quite confident in the upcoming victory. This will allow us to test further whether the ability to blame someone impacts the negative spill-over of the unexpected loss.

Using this idea of certainty, we can test how people respond to unexpected losses given certainty as well as referee fatigue. To do this without getting into too many interactions, we simply partition the data into games above or below the median level of certainty and above or below the median fatigue level. Next, we estimate regression models like in Card and Dahl (2011). Table 8 explains the partitioning of the data. Since average number of days off for the referee crew is nearly discrete, whether or not the median is included in a certain group might effect the results of the test. In this table, games with the median amount of rest are dropped in the first section of rows, games with the median amount of rest are included in the "Tired" category in the second section, and games with the median amount of rest are included in the "Rested" category in the third.

Table 8: Number of Observations for Each Category

\begin{tabular}{l|r|r|r} 
& Low Rest & Med. Rest & High Rest \\
\hline Low SD & $470(24)$ & $611(28)$ & $356(17)$ \\
Med. SD & $866(23)$ & $1171(37)$ & $739(22)$ \\
High SD & $422(20)$ & $669(41)$ & $410(18)$ \\
\hline
\end{tabular}

Note: The number of unexpected losses are presented here in parentheses.

The estimates for unexpected losses can be seen in Table 9. The results of this indicate that regardless of the certainty felt towards the game, as measured through the standard deviation, an effect for tired referees persists. However, depending on how the sample is divided, the effect is bigger for games where the market is more vs less certain though statistically indistinguishable from zero. Effects for violence appear to concentrate in games where there is more uncertainty (higher standard deviation) in the game outcome. A well-developed literature on the causes of family violence finds identifies risk-taking gambling behavior as a characteristic among many violent offenders (Dowling et al., 2016). Our results suggest that games where the outcome is more uncertain and referees are not rested, in-home family violence increases.

Table 9: Differences in Betting Confidence, SE CL at County level

\begin{tabular}{l|cc|cc|cc} 
& \multicolumn{2}{|c|}{ Low Rest } & \multicolumn{2}{c|}{ Med. Rest } & \multicolumn{2}{c}{ High Rest } \\
\hline Low SD & 0.035 & 0.03 & $0.117^{* * *}$ & $0.106^{* *}$ & -0.018 & -0.003 \\
& $(0.067)$ & $(0.07)$ & $(0.036)$ & $(0.042)$ & $(0.055)$ & $(0.053)$ \\
& & & & & & \\
\hline Med. SD & 0.088 & $0.119^{* * *}$ & 0.037 & 0.036 & $-0.076^{*}$ & -0.066 \\
& $(0.056)$ & $(0.028)$ & $(0.053)$ & $(0.067)$ & $(0.045)$ & $(0.042)$ \\
& & & & & & \\
\hline High SD & $0.195^{* *}$ & $0.157^{* * *}$ & 0.009 & -0.007 & -0.089 & -0.007 \\
& $(0.079)$ & $(0.051)$ & $(0.04)$ & $(0.033)$ & $(0.095)$ & $(0.069)$ \\
& & & & & & \\
\hline
\end{tabular}

Note: These coefficients are the result of a poisson regression that sorts games into categories. These represent the effect upset losses and their respective standard deviation \& rest combination have on Family Violence. Standard errors are clustered by county. 


\subsection{Empirical Winning Probability}

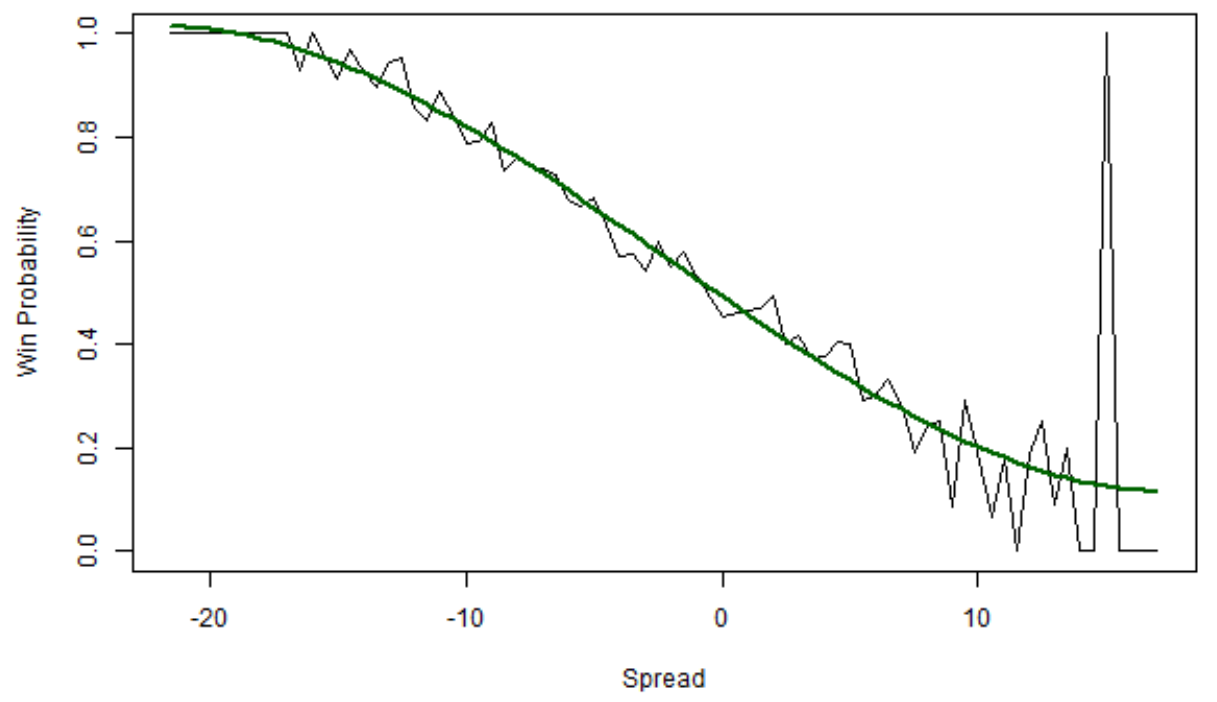

Figure 5: Empirical Probability of Winning, given Point Spread

\subsubsection{Time Series Family Violence Across Counties}

Figure 6 contains time series plots of monthly incidents occurring in each county in the sample. Differences in variation appear uniform and suggest a robust sample of incidents across the counties in our sample.

Figure 6: Normalized Family Violence Time Series By County

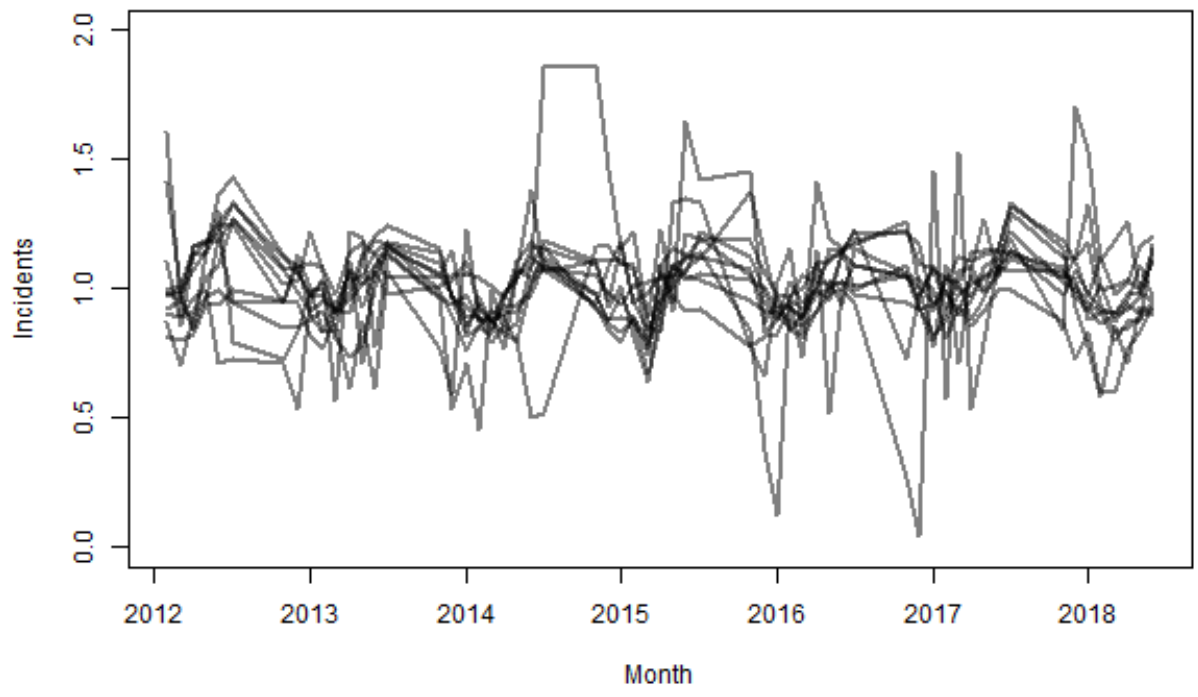




\subsection{Referee Fatigue}

\subsubsection{Referee Assignment}

An argument that might arise is that the NBA could be strategically assigning referees to games in a way that resulted in better referees officiating more games, and thus having less rest. However, if this is the case, then the idea that referee ability being correlated with rest would only upward bias our negative result 14 Regardless, to ensure that we are indeed capturing referee fatigue and not a proxy for referee ability, we plot the a few different variables against one another.

In Figure 7, we plot referee rest by the number of games they officiate. Here we find that as the number of games increases, average rest decreases. This is intuitive since average rest should be the number of days in the season divided by the number of games officiated. If there were 82 days in an 82 game season, on average one game would be played every day making average rest to be 1 day. If there were 164 days and 82 games, average rest would be 2, and so on. There are two interesting caveats about this plot, though. First, one can see a band of X's extremely low on the plot relative to the other points. This is the 2011-12 season, where the NBA had a lockout. Here, the NBA needed to squeeze in as many games as possible in just over half the time of a regular season. Therefore, players and referees alike were unusually fatigued all season. Second, the +'s seem to cutoff right around the 60 game mark. These depict referees in the 2017-18 season. The NBA seems to have hired a handful of extra referees this year, thus decreasing the number of games for each referee.

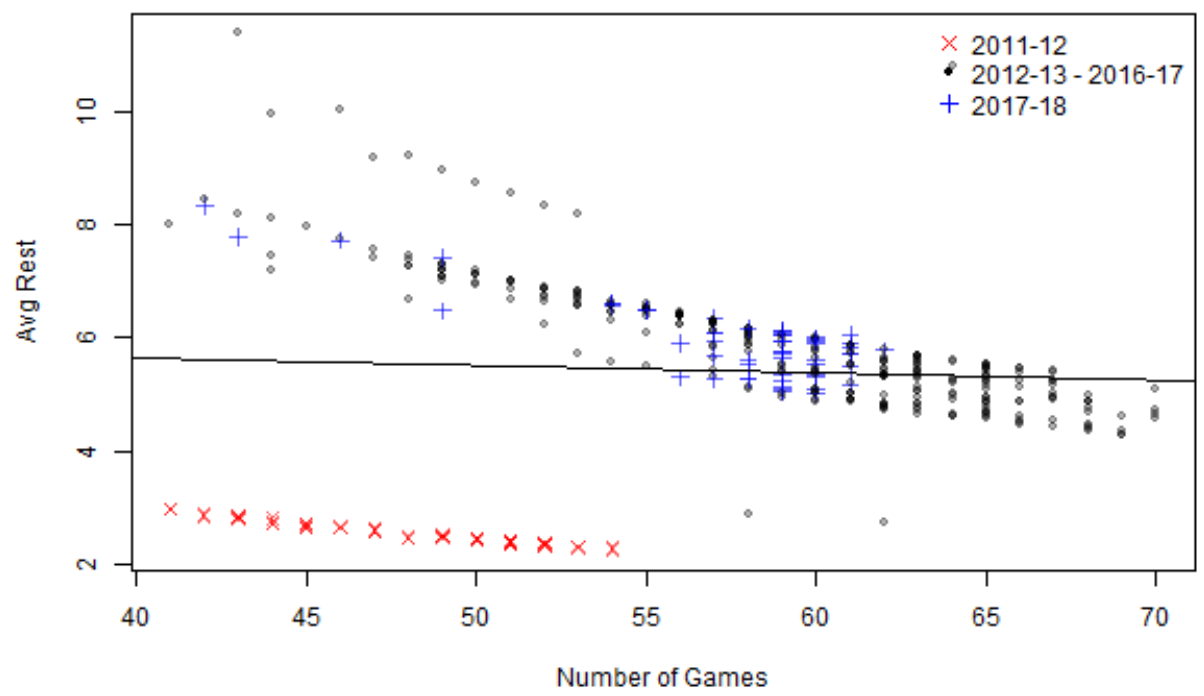

Figure 7: Avg. Rest by \# of Games Officiated

This plot does not alleviate the potential of better, or more experienced, referees officiating more games. Using experience as a proxy for ability, Figure 8 shows a shotgun distribution between the number of games refereed and the experience of a referee, suggesting no relationship between the two. Lastly, Figure 9 plots average rest against experience and again finds a smattering of points with no visible relationship after the

\footnotetext{
${ }^{14}$ maybe this is better placed later in the paper - robustness section?
} 
first few years of experience for referees. In the collective bargaining agreement, a referee is granted the status of "veteran" after three years of more than 25 games. There appears to be a downward slope until about 4 or 5 years, and then a mostly flat line. These plots suggest that referee experience and days of rest are uncorrelated.

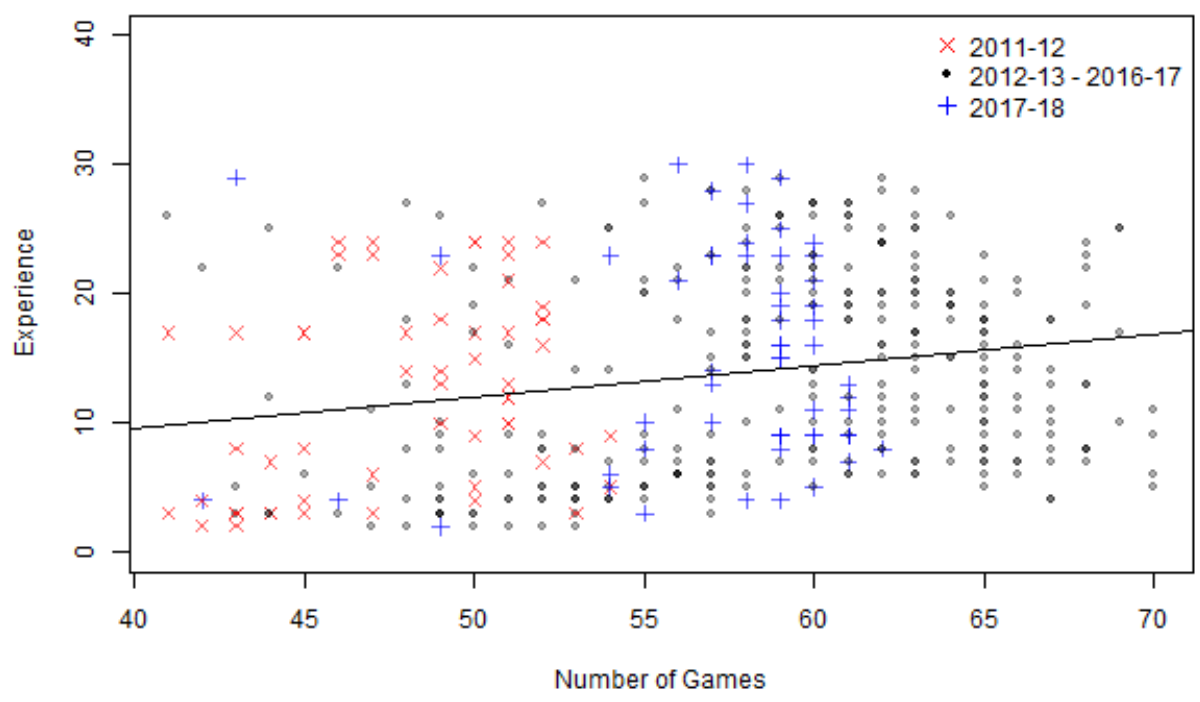

Figure 8: Referee Experience by \# of Games Officiated

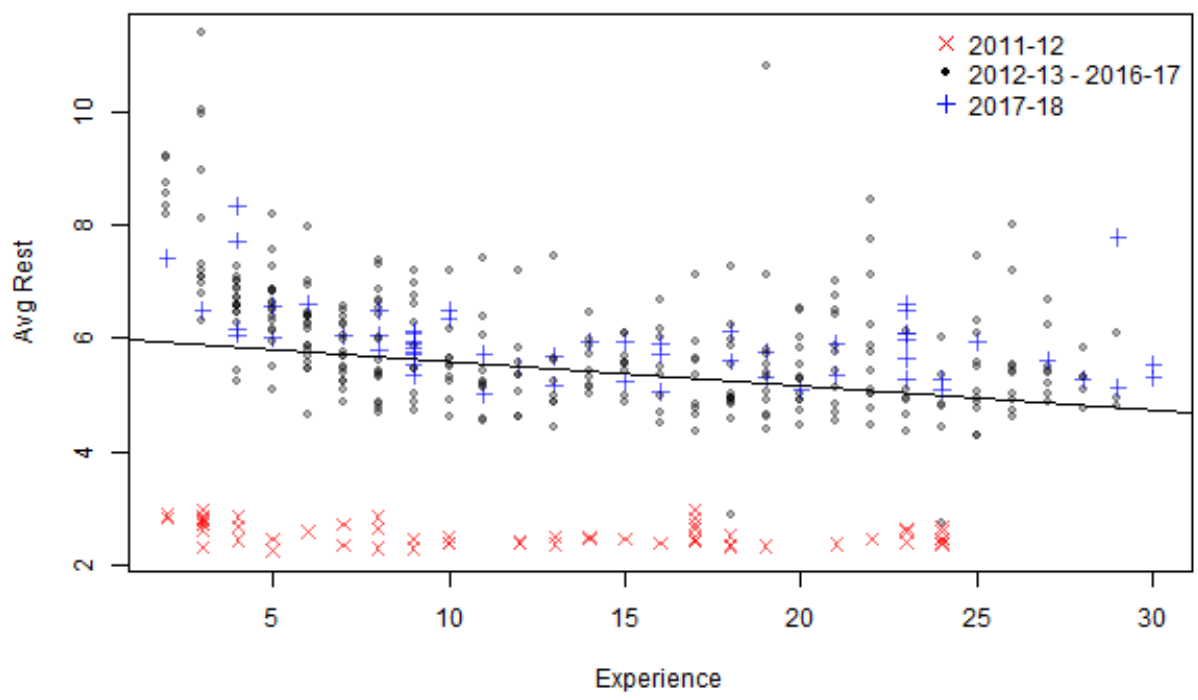

Figure 9: Referee Experience by Avg. Rest 


\subsubsection{Referee Travel Maps}

Figure 10: Example Travel Paths for NBA Referees: Zach Zarba
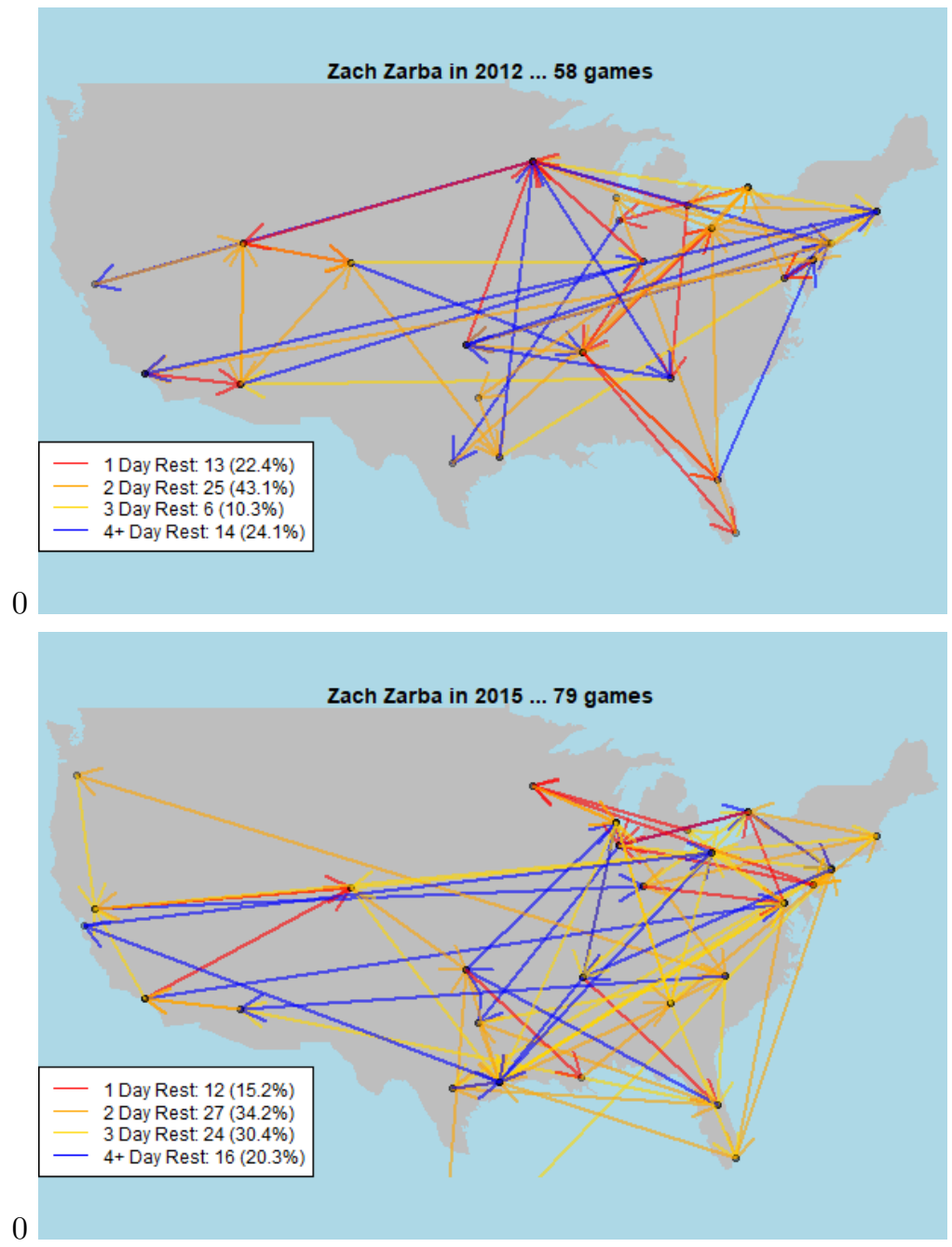

0

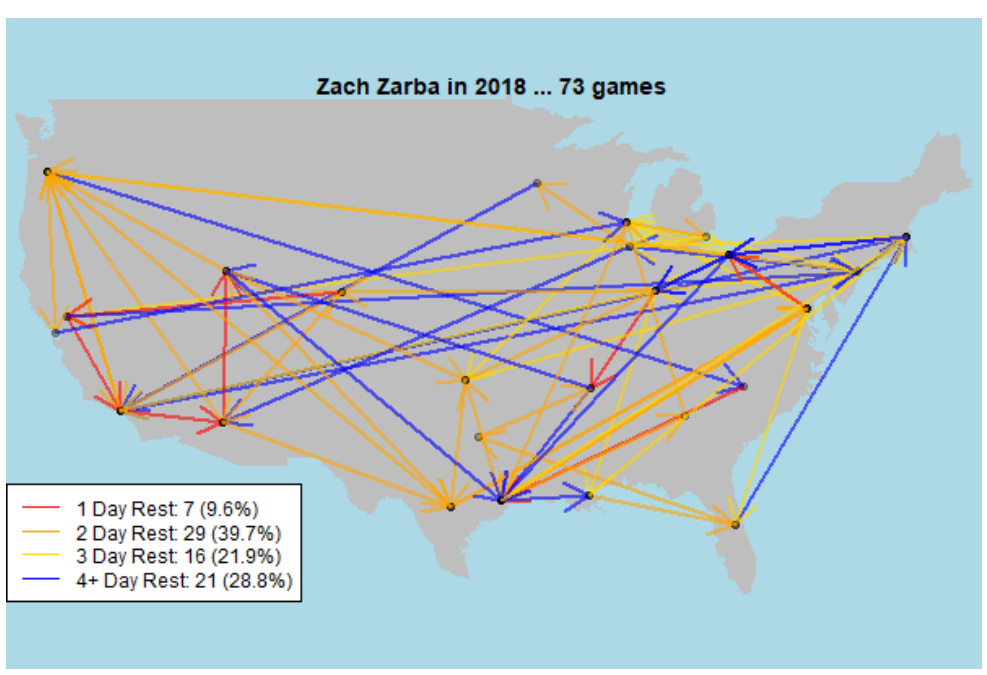




\subsection{Distribution of SportsPlays.com Consensus Bets}

Figure 11: Betting Volume by Game

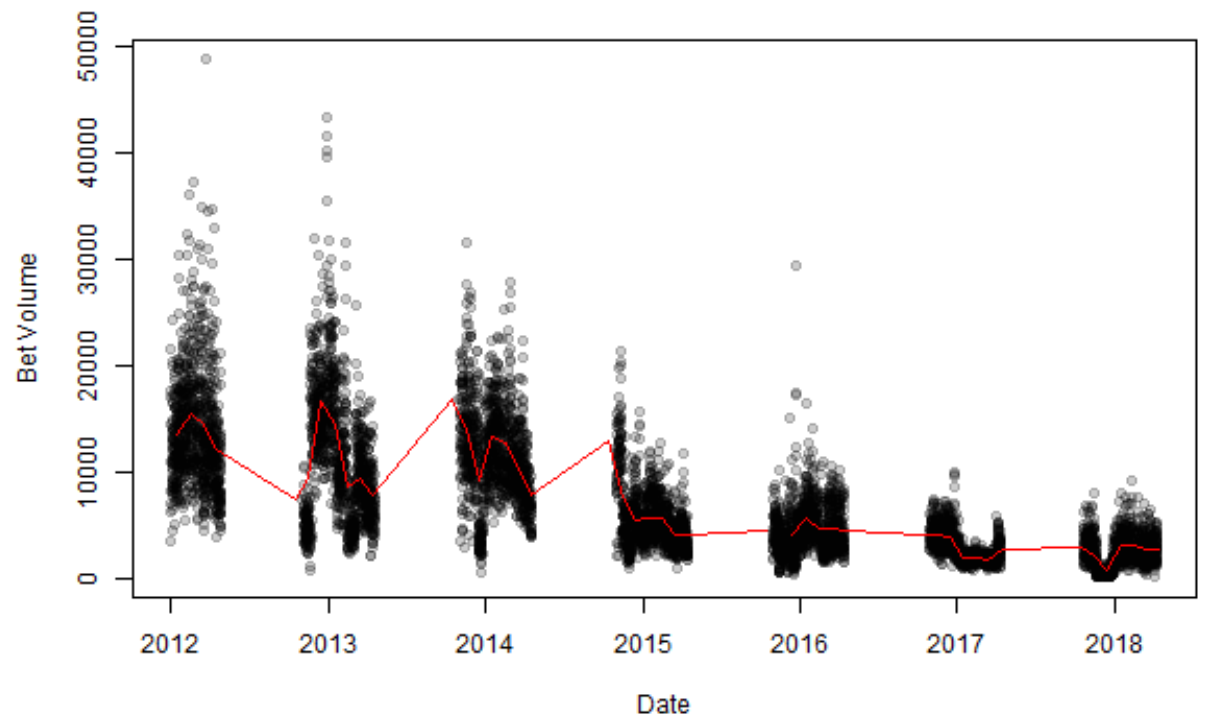

\subsection{Number of Nationally Televised Cavalier Games by NBA Season}

Figure 12: Number of Nationally Televised Cleveland Cavalier Games by NBA Season

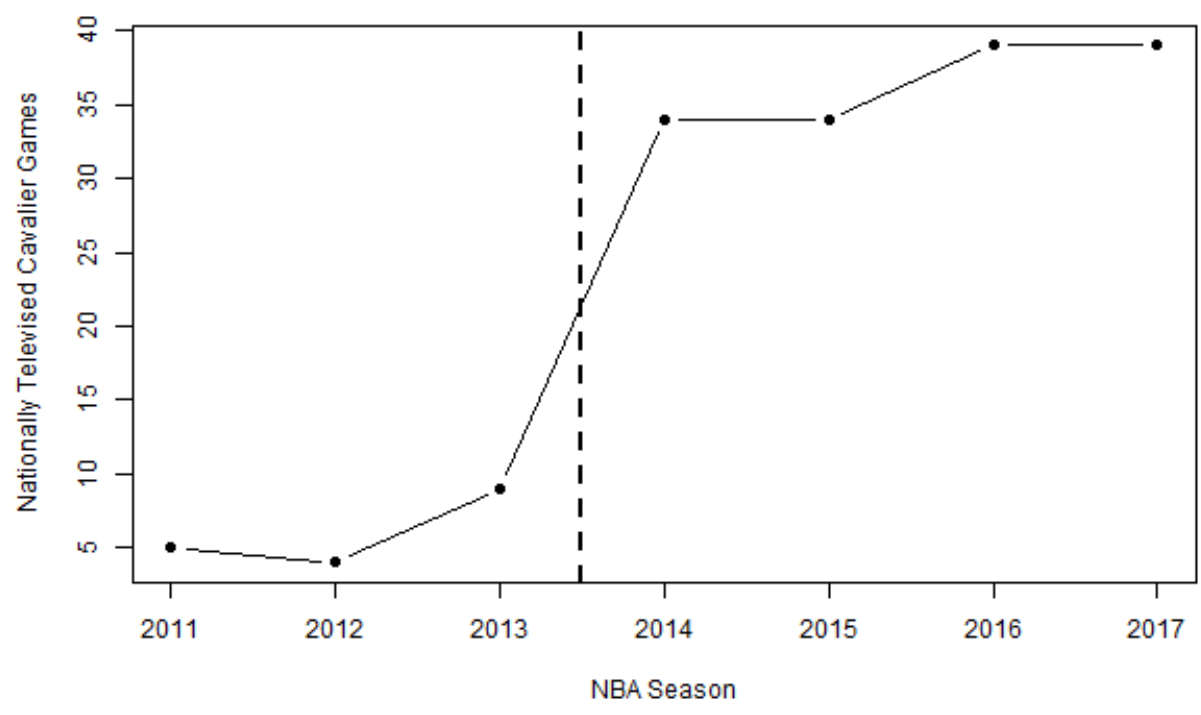

